Article

\title{
Application of a Non-carrier-Based Modulation for Current Harmonics Spectrum Control during Regenerative Braking of the Electric Vehicle
}

\author{
Marcin Steczek $^{1, *(1)}$, Piotr Chudzik ${ }^{2}$ and Adam Szeląg 1 ([) \\ 1 Faculty of Electrical Engineering, Institute of Electrical Power Engineering, Warsaw University of \\ Technology, 00-661 Warszawa, Poland; adam.szelag@ee.pw.edu.pl \\ 2 Faculty of Electrical Engineering, Institute of Automatic Control, Lodz University of Technology, \\ 90-924 Łódź, Poland; piotr.chudzik@p.lodz.pl \\ * Correspondence: marcin.steczek@ien.pw.edu.pl
}

Received: 21 November 2020; Accepted: 14 December 2020; Published: 18 December 2020

\begin{abstract}
The regenerative braking of railway vehicles is widely used in DC railway systems all over the world. This mode of operation provides an opportunity to reuse part of the energy consumed by vehicles, and makes the railway system more energy efficient. During regenerative braking, not only energy management is an issue, but also Electromagnetic Compatibility EMC issues, such as interference of generated current harmonics with a railway signaling system. In this paper, the selective harmonic elimination modulation technique (SHE-PWM) was introduced to the traction drive with a three-level inverter to reduce specific catenary current harmonics generated during regenerative braking. The simulation model of a traction drive appropriate for harmonics analysis was proposed and verified by the measurements in the low-power laboratory drive system. The model was re-scaled to the $3 \mathrm{kV}$ DC system for further study. The model of an induction motor with electromotive force and the method of its calculation was proposed. Furthermore, an analysis of the braking chopper operation was carried out. The asymmetric control of braking chopper was proposed to reduce the current harmonics below limits during chopper operation.
\end{abstract}

Keywords: selective harmonic elimination; regenerative braking; railway vehicle; EMC

\section{Introduction}

The regenerative braking of the rolling stock gives an opportunity to reduce energy consumption in electric transportation systems like railways, trams, and metro. The higher traffic density, the higher energy-saving can be achieved. However, the regenerative braking of a vehicle in the system changes its character from being a load to being a source. Therefore, this operating mode requires a separate approach to the issues solved for the tractive operation, such as the generation of current harmonics and compatibility with the railway signaling system.

One of the issues in the electric transportation system, with vehicles equipped with regenerative braking, is energy management. Studies can be found for metros [1], DC railway systems [2], and AC high-speed railway [3] where authors analyze and optimize the energy flow between braking vehicles, accelerating vehicles, and energy storage systems (ESS) [4,5]. The development of ESS is one of the options for increasing the reuse of regenerated energy. Thus, the development of topology and sizing of the ESS is crucial for application [6-8]. In DC systems, the flow of the regenerated energy is terminated by rectifiers at the substations, which is the cause of limited receptivity of the DC systems [9]. To unblock the flow of the energy from the DC railway or metro system reversible substations with inverters are being used $[10,11]$. 
Another system level approach to the problem of increasing efficiency of the energy regeneration is the optimization of an Automatic Train Operation (ATO) system [12]. The adjustment of vehicles' trajectories in multivehicle systems can result in energy-saving up to 19\% [13].

Energy efficiency and performance of the rolling stock require the use of high power converters for traction and regenerative braking [14], leading to a wide range of EMC problems between the vehicles and the supply infrastructure (e.g., harmonic distortion [15], instability [16]) and towards command-control systems as well [17] (e.g., resonances [18], radio interference, including wireless systems [19]). It was observed that harmonics present in traction currents flowing in rails could cause disturbances in the operation of signaling systems, track circuits, and axle counters [20], in particular. Research works on new solutions applied in traction drives supplied by $3 \mathrm{kV}$ DC could reduce energy losses and EMC problems [21]. It is a complex issue due to the variability of applied technical solutions and phenomena which are to be taken into account (resonances, and non-linearities of elements [22]), and different systems which could be disturbed (signaling, command and control, and especially track circuits). European regulations require confirmation of compatibility between rolling stock and track infrastructure [23]. Therefore railway infrastructure operators were imposing limits of electric vehicle current harmonics in order to assure the safety of traffic on railway lines. It was significantly important in counties when the modern rolling stock was put into service on railway lines with track circuits, as for example in Poland [24]. Some examples of such limits versus frequency are shown in Figure 1 [25] and Figure 2. [26]. Limits imposed by Polish railways in the 1990s of the XX century were too strict comparing with other railway operators; they were too difficult to be fulfilled by newly introduced rolling stock, leading to these limits being eased—as shown in Figure 3. [27]. Typically, research on compatibility issues was focused on traction currents taken by a vehicle operating in a driving mode. However, during recuperative braking, harmonics in current delivered from a vehicle to catenary must be within the defined limits [27].

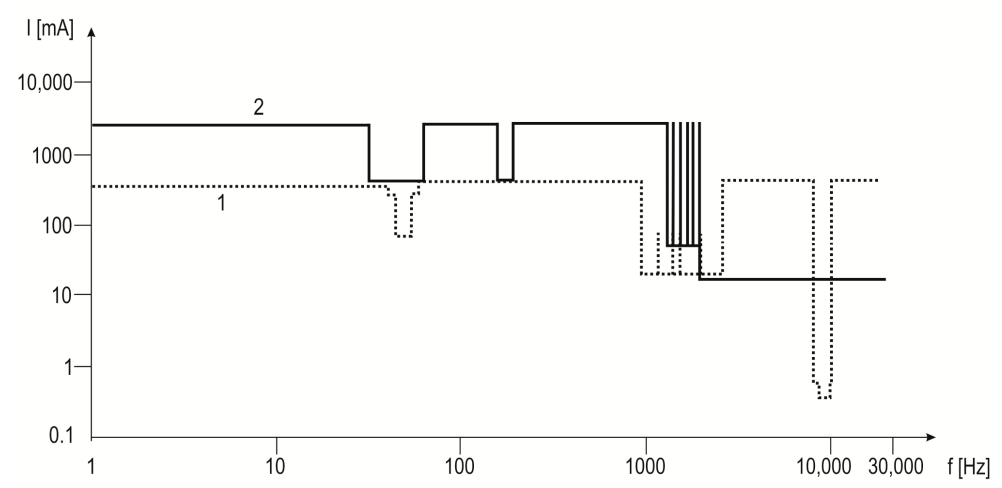

Figure 1. Comparison of limits imposed on harmonics in traction vehicles current supplied by $3 \mathrm{kV} D C$ system on Polish railways in the 90s of the XX century (1) and on Italian railways (2) [25].

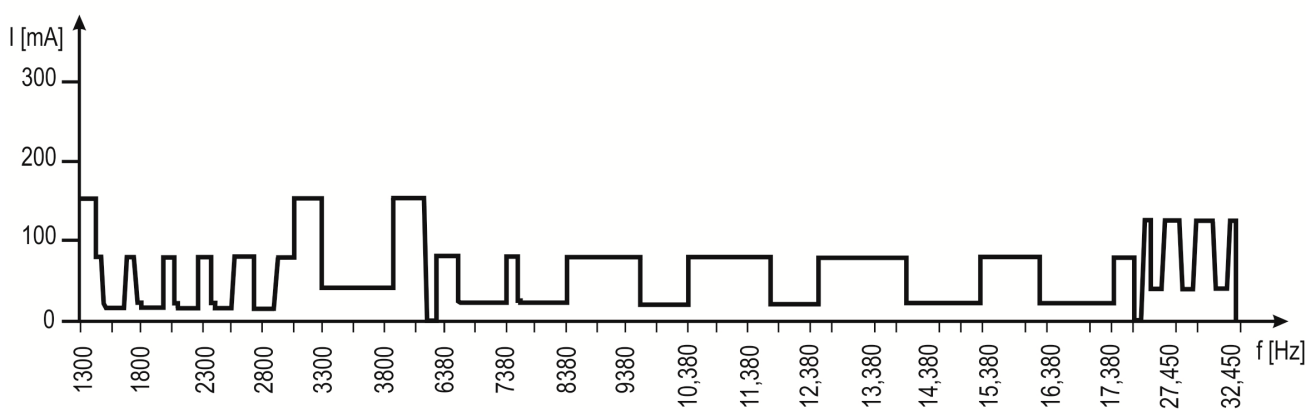

Figure 2. Modified limits of harmonics in vehicle/s current supplied by $3 \mathrm{kV}$ DC voltage [26]. 


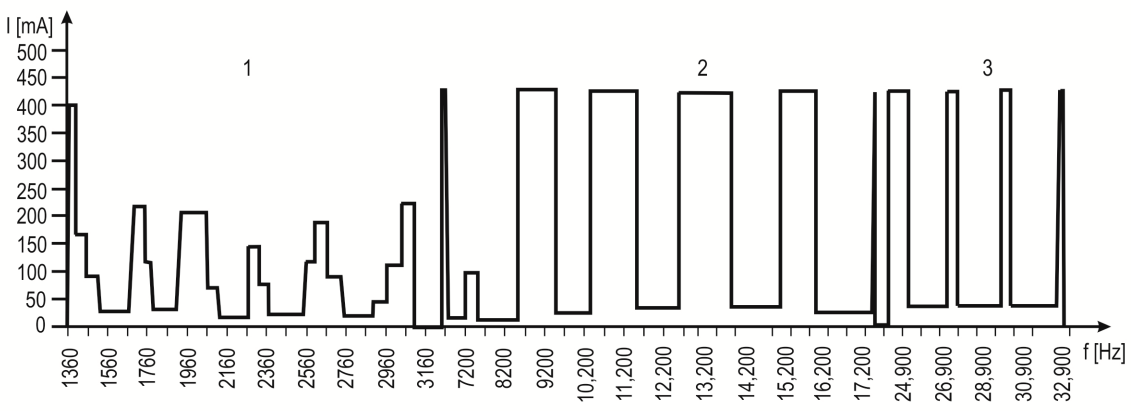

Figure 3. Currently applicable limits of harmonics in vehicle's current on Polish railway lines [27] for a range of frequencies according to types of track circuits applied $(1,2,3)$.

This paper concerns theoretical, and simulation analyses of a spectrum of recuperation current harmonics. This research was also confirmed by measurements using a laboratory stand.

Figure 4 presents the power supply system of the DC railway line where the braking vehicle is transferring the regenerated energy via catenary to an accelerating vehicle. The area of possible interference between current harmonics generated by a drive of a braking vehicle ( $\mathrm{I}_{\text {cat }}$ - catenary current) and the railway signaling (RS) systems ( $\mathrm{I}_{\mathrm{S}}$ - control signal).

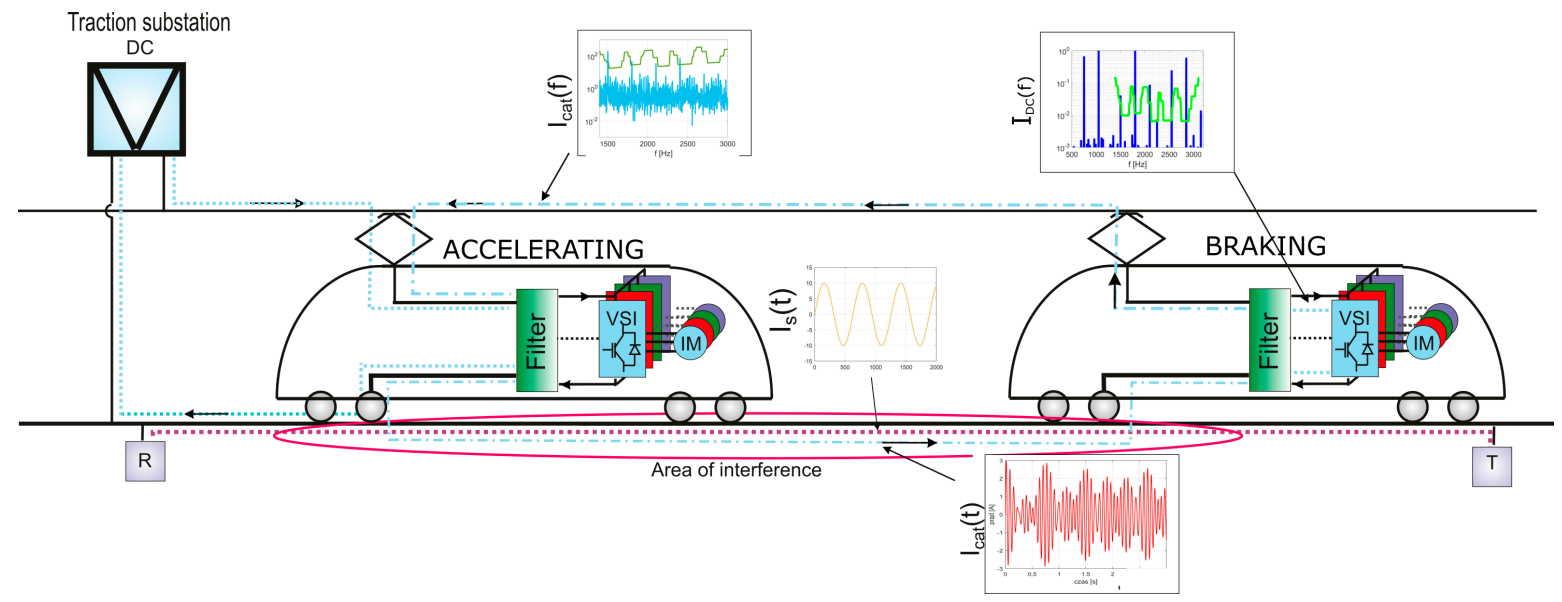

Figure 4. Simplified scheme of the railway power supply system and the area of possible interference between harmonics from braking vehicle and RS system.

\section{Methodology}

The methodology used for the study presented in this article was based on the use of the simulation model of a traction drive ( $3 \mathrm{kV}$ DC-500 kW) verified in the laboratory scale $(0.6 \mathrm{kV} \mathrm{DC}-2.5 \mathrm{~kW})$. The simulation model, after being verified, was rescaled to the $3 \mathrm{kV} D C$ and used to analyze the circulation of the current harmonics during regenerative braking in the $3 \mathrm{kV}$ DC traction system. Only steady states were taken under consideration, and an Fast Fouries Transform (FFT) algorithm was used to determine harmonics amplitudes.

\subsection{Simulation Model of the Drive}

Figure 5 presents a simulation model of the drive used for the purpose of this work. It consists of a Voltage Source Inverter (VSI) with a braking circuit and a model of an induction machine. Figure 5b presents two types of the equivalent circuit of one phase of an induction motor. Circuit MOD1 from Figure $5 \mathrm{~b}$ is suitable only for simulations for a fundamental component of a phase current. In MOD1 the load is represented by an additional series resistance $R_{\text {load }}$ in the rotor's branch. The $R_{\text {load }}$ should affect only the fundamental component of the rotor's current I'r. However, it will suppress all higher 
harmonics. For higher harmonics, $R_{\text {load }}$ should be close to zero, and due to the slip is close to 1 . In this work, the authors tested the MOD2 model from Figure 5b, where resistance $R_{\text {load }}$ was replaced by Electromotive Force (EMF) modelled as a voltage source where $\mathrm{V}_{\mathrm{EMF}}$ is a modulo and $\varphi_{\mathrm{EMF}}$ is an argument. Solving the Figure 5a (MOD2) equivalent circuit, the EMF is represented by the following formula:

$$
\overline{E M F}=\left(\frac{\overline{V_{p h}}-\overline{Z_{s}} \cdot \overline{I_{p h}}}{\left(\overline{Z^{\prime} r}+R_{\text {load }}\right)}\right) \cdot R_{\text {load }}
$$

where:

$\overline{Z^{\prime}{ }_{r}}=R^{\prime}{ }_{r}+j \omega L^{\prime}{ }_{r}$ is rotor's impedance,

$\overline{Z_{s}}=R_{s}+j \omega L_{s}$ is stator's impedance,

$R_{\text {load }}=R^{\prime}{ }_{r} \cdot\left(\frac{1-s}{s}\right)$ is additional resistance in rotor replaced by EMF,

$\overline{I_{p h}}=\frac{\overline{V_{p h}}}{\bar{Z}}$ is motor's phase current.

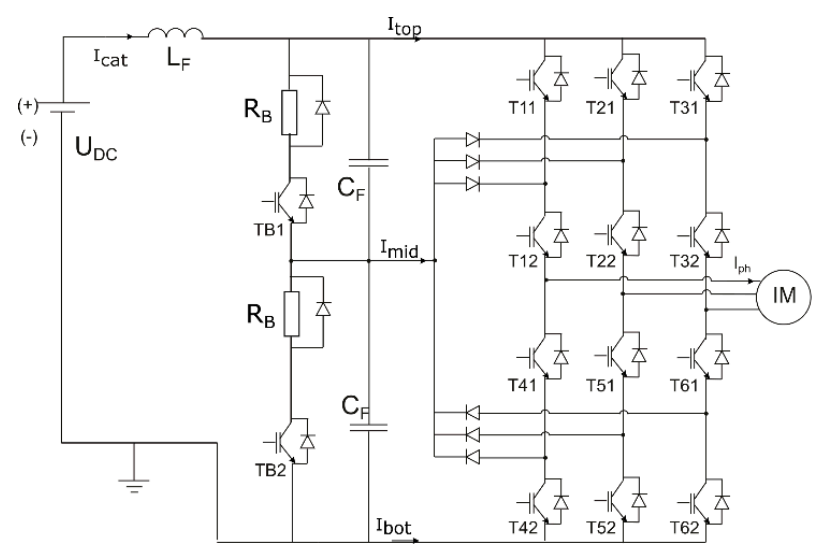

(a)

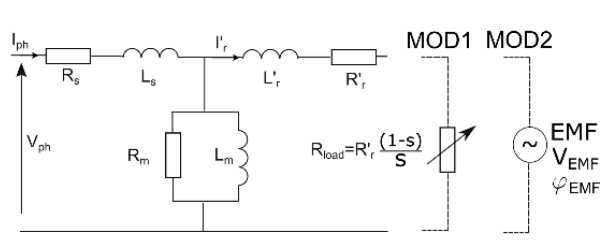

(b)

Figure 5. The simulation model (a) 3-lvl VSI a with braking circuit (b) equivalent circuit of the one phase of an induction model (MOD1: load modelled as resistance; MOD2: load modelled as a voltage source).

In this work, two drives have been considered (Table 1). The real-size drive (3KVM motor model) has been used for mathematical simulations of $3 \mathrm{kV}$ drive system. The laboratory-size drive (two Siemens 1LA7106 motors-breaking and driving) has been used for real model verification in small scale.

Table 1. Parameters of the laboratory-size and full size-traction drives.

\begin{tabular}{ccc}
\hline Type & $\begin{array}{c}\text { Siemens 1LA7106 } \\
\text { (Motor) }\end{array}$ & 3KVM (Model) \\
\hline Rated power-Pn & $2.2 \mathrm{~kW}$ & $500 \mathrm{~kW}$ \\
Rated current-In & $4.85 \mathrm{~A}$ & $170 \mathrm{~A}$ \\
Rated voltage-Un & $400 \mathrm{~V}$ & $1900 \mathrm{~V}$ \\
Stator leakage inductance per-phase-Ls & $10.8 \mathrm{mH}$ & $1.56 \mathrm{mH}$ \\
Stator winding resistance per phase-Rs & $2.84 \Omega$ & $0.107 \Omega$ \\
Rotor leakage inductance per-phase-L'r & $10.6 \mathrm{mH}$ & $1.6 \mathrm{mH}$ \\
Rotor resistance per phase-R'r & $2.73 \Omega$ & $0.07 \Omega$ \\
Core loss resistance-Rm & $1200 \Omega$ & $\infty$ \\
Magnetizing inductance-Lm & $275 \mathrm{mH}$ & $53 \mathrm{mH}$ \\
\hline
\end{tabular}




\subsection{Selective Harmonic Elimination}

The selective harmonic elimination technique is well studied and described in the literature [28]. This technique is an arbitrary type modulation which imposes switching times for each transistor (switching angles). It has no reference or carrier signal, like in other modulation methods. Switching angles determines the shape of the switching function for transistors which develops the inverter's output voltage waveform. There are numerous techniques for determining switching angles. One of the most popular is based on the Particle Swarm Optimization (PSO) algorithm [29]. However, most of the techniques [30,31] are based on the development of the Fourier Series (2) into the set of nonlinear Equation (6).

$$
f(\omega t)=a_{0}+\sum_{n=1}^{\infty}\left[a_{n} \sin (n \omega t)+b_{n} \cos (n \omega t)\right]
$$

where: $a_{0}, a_{n}$ and $b_{n}$ : coefficients described by the Euler's formulas.

Assuming quarter-wave symmetry, the function has to fulfil the following conditions:

$$
\begin{gathered}
f(\omega t)=-f(\omega t+\pi) \\
f(\omega t)=f(\pi-\omega t)
\end{gathered}
$$

For quarter-wave symmetry the coefficients $a_{0}$ and $b_{n}$ are equal to zero and for the three-level (Figure 2), the coefficient $a_{n}$ is given by:

$$
a_{n}= \begin{cases}\frac{2 \cdot U_{D C}}{2 n \pi}\left[1+\sum_{i=1}^{N}(-1)^{i} \cdot \cos \left(n \cdot k_{i}\right)\right] & \text { for odd } n \\ 0 & \text { for even } n\end{cases}
$$

The set of nonlinear equations for $N=5$ switching angles and 3 level inverter is as follows:

$$
\left\{\begin{array}{c}
\frac{2}{\pi}\left[1-\cos \left(\alpha_{1}\right)+\cos \left(\alpha_{2}\right)-\cos \left(\alpha_{3}\right)+\ldots\right. \\
\left.\ldots \cos \left(\alpha_{4}\right)-\cos \left(\alpha_{5}\right)\right]=M 1 \\
\frac{2}{5 \pi}\left[1-\cos \left(5 \alpha_{1}\right)+\cos \left(5 \alpha_{2}\right)-\cos \left(5 \alpha_{3}\right)+\ldots\right. \\
\left.\ldots \cos \left(5 \alpha_{4}\right)-\cos \left(5 \alpha_{5}\right)\right]=0 \\
\frac{2}{7 \pi}\left[1-\cos \left(7 \alpha_{1}\right)+\cos \left(7 \alpha_{2}\right)-\cos \left(7 \alpha_{3}\right)+\ldots\right. \\
\left.\ldots \cos \left(7 \alpha_{4}\right)-\cos \left(7 \alpha_{5}\right)\right]=0 \\
\frac{2}{11 \pi}\left[1-\cos \left(11 \alpha_{1}\right)+\cos \left(11 \alpha_{2}\right)-\cos \left(11 \alpha_{3}\right)+\ldots\right. \\
\left.\ldots \cos \left(11 \alpha_{4}\right)-\cos \left(11 \alpha_{5}\right)\right]=0 \\
\frac{2}{13 \pi}\left[1-\cos \left(13 \alpha_{1}\right)+\cos \left(13 \alpha_{2}\right)-\cos \left(13 \alpha_{3}\right)+\ldots\right. \\
\left.\ldots \cos \left(13 \alpha_{4}\right)-\cos \left(13 \alpha_{5}\right)\right]=0
\end{array}\right.
$$

where: $M 1$ is for modulation index:

$$
V_{1}=M 1 \frac{U_{D C}}{2} ; \quad \text { for } M 1\left\langle 0, \frac{4}{\pi}\right\rangle
$$

The set of Equation (6) can be solved using an optimization algorithm. In such a case the fitness function must be formulated and minimized. The example of a fitness function for $N=5$ switching angles is the following:

$$
\begin{gathered}
\text { Minimize, } f_{f i t}\left(\alpha_{1}, \alpha_{2}, \alpha_{3}, \alpha_{4}, \alpha_{5}\right)=\sigma_{1} \cdot\left(V_{1}-V_{1}^{*}\right)^{2}+\sigma_{5} \cdot\left(V_{5}\right)^{2}+ \\
\sigma_{7} \cdot\left(V_{7}\right)^{2}+\sigma_{11} \cdot\left(V_{11}\right)^{2}+\sigma_{13} \cdot\left(V_{13}\right)^{2} \\
\text { subject to: } 0<\alpha_{1}<\alpha_{2}<\alpha_{3}<\alpha_{4}<\alpha_{5}<\frac{\pi}{2}
\end{gathered}
$$


where: $V_{1}$ is a fundamental component, and $V_{5}, V_{7}, V_{11}, V_{13}$ are 5th, 7th, 11th and 13th voltage harmonics (p.u.) respectively, $\sigma_{x}$ are penalty weights for the optimization process.

The result of the optimization process is determination of the switching angles. In the three-level Neutral Point Clamped Voltage Source Inverter (NPC VSI) the switching function is realized by four transistors for each phase $\left(T_{n 1}, T_{n 2}, T_{n 3}, T_{n 4}\right.$-where $n$ is phase number). $T_{n 1}$ transistors operates in positive half of the period. $T_{n 4}$ transistors operates in negative half of the period and $T_{n 2}, T_{n 3}$ transistors operate as negations of $T_{n 4}, T_{n 1}$, respectively. Figure 6 presents the division of the switching function developed of upper transistors in the inverter's leg (refer to Figure 5).
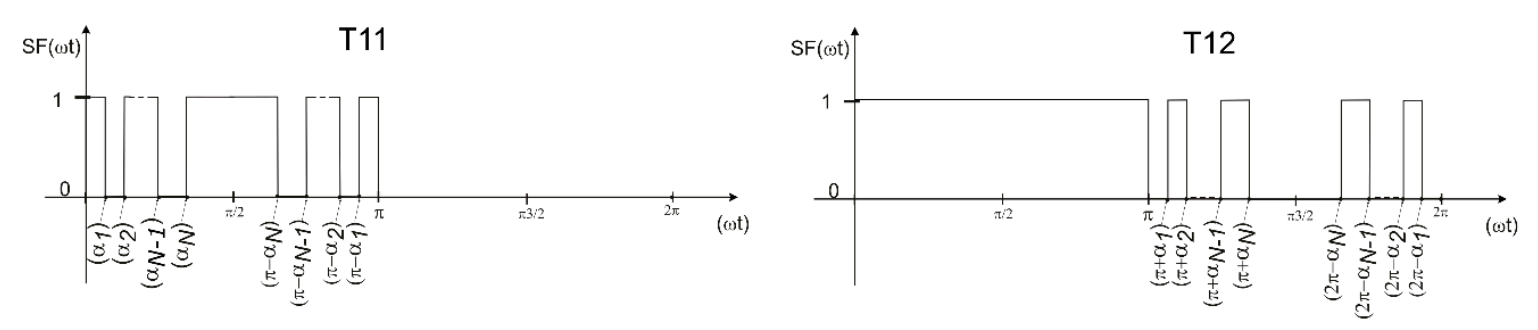

Figure 6. Implementation of switching angles in the switching function for three-level inverter.

In this work, the SHE-PWM was used to affect the spectrum of catenary current $\left(\mathrm{I}_{\mathrm{cat}}\right)$ by control of harmonics of the inverter's output current (phase current of the motor).

\subsection{Laboratory Setup and Measurements}

The model verification was conducted with the laboratory setup (Figure 7). The parameters of the equivalent circuits are listed in Table 1.

The stand consists of two drive systems:

- Driving system built from the Invertec P2 inverter, which drives the first Siemens 1LA7106 motor.

- Breaking system, built of a specially designed laboratory 3-level inverter, which controls the voltage of the second Siemens 1LA7106 motor. The control of transistors, in the case of the Selective Harmonic Elimination (SHE) algorithm, is carried out in the DSPACE 1104 card, using the Look UP tables, created in the MATLAB. The control of transistors, in the case of the Sinus Pulse Width Modulation (SPWM) algorithm, is carried out in the DSPACE 1104 card, using a timer system, created in the MATLAB-Simulink.

The verification consisted of the DC-link currents ( $\mathrm{I}_{\text {bot }}, \mathrm{I}_{\mathrm{mid}}, \mathrm{I}_{\text {top }}$-Figure 5a) comparison between results of measurements and simulations. The spectra of inverter's DC-link currents and motor's phase currents have been compared. The first comparison was made for SPWM modulation. The drive was performing regenerative braking with phase current $\mathrm{I}_{\mathrm{ph}}=7.4 \mathrm{~A}$. During the experiment, the braking motor was driven with constant rotating speed by an induction motor (Driving motor and fed with a Driving inverter). Regenerated energy was dispersed in a resistor $(120 \Omega)$. Braking choppers were not active, and a voltage measured in DC-link was 600 V. Figures 8 and 9 present the comparison between the experimental results and simulations. Presented results have been obtained for modulation index $\mathrm{M} 1=0.9$, carrier frequency $\mathrm{f}_{\mathrm{c}}=850 \mathrm{~Hz}$ and fundamental frequency $\mathrm{f}_{\mathrm{f}}=50 \mathrm{~Hz}$.

The same methodology of comparison between measurements and simulations was applied for SHE modulation. The SHE-PWM used in this part of research represents M1 $=0.9$ and $\mathrm{f}_{\mathrm{f}}=50 \mathrm{~Hz}$ with $\mathrm{N}=9$ switching angles in quarter period. The following voltage harmonics: 5 th, 7 th, 11 th, 13 th, 17th, 19th, 29th, 31st have been eliminated from output voltage waveform. The fundamental of the phase current was $\mathrm{I}_{\mathrm{ph}}=7 \mathrm{~A}$. Harmonics in three wires of a 3-level inverter were compared in terms of simulations and measurements (Figure 9). Thus, on the basis of results presented in this section, the authors claim that the proposed model and methodology has been validated and can be applied for further analysis. 


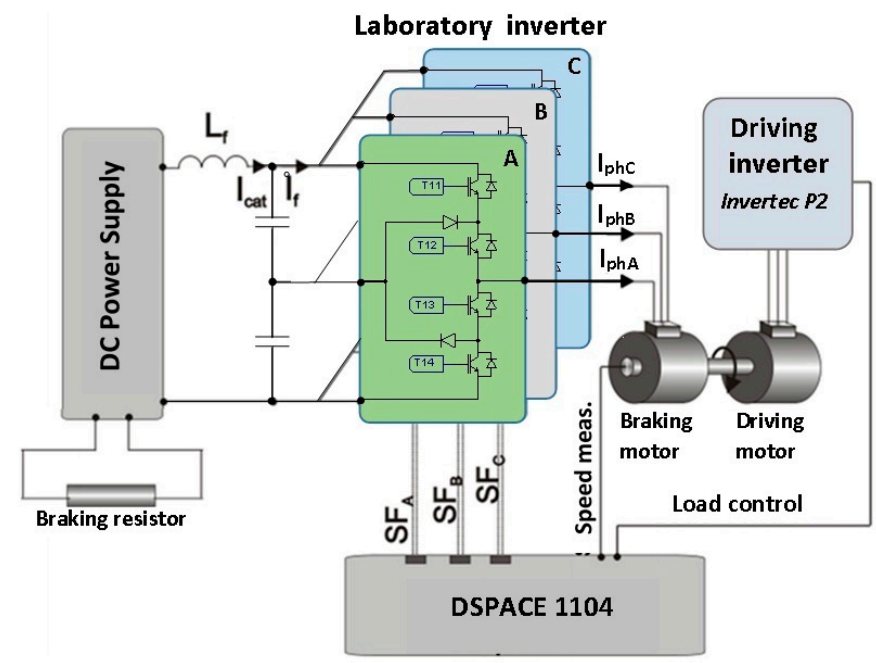

(a)

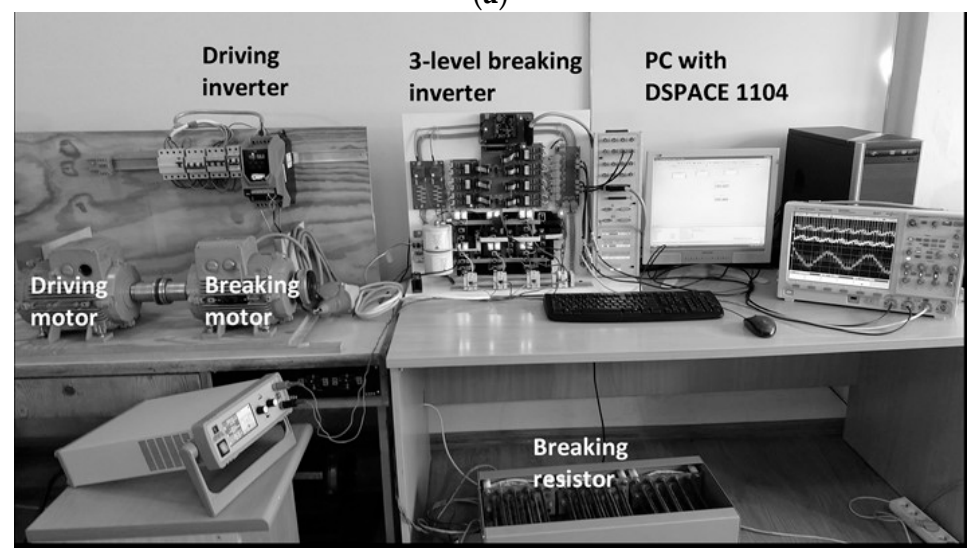

(b)

Figure 7. The laboratory setup: (a) simplified scheme, (b) laboratory stand.

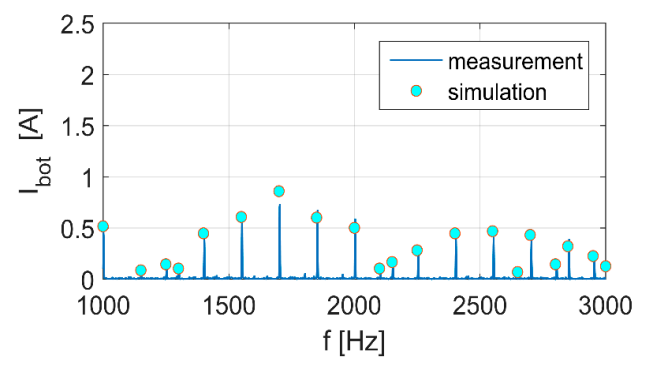

(a)

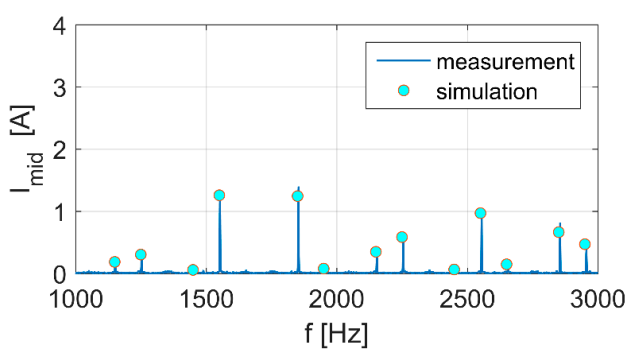

(b)

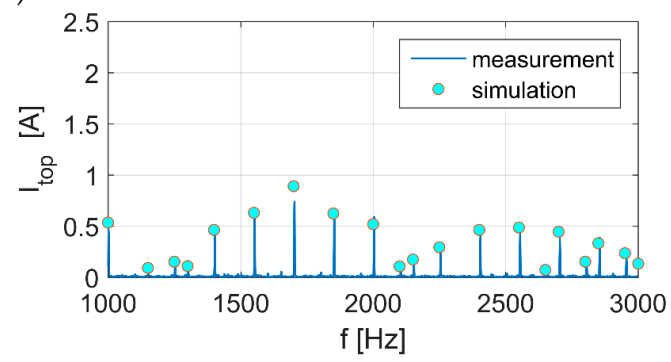

(c)

Figure 8. Spectrum of DC-link currents in VSI NPC inverter with SPWM (a) current $\mathrm{I}_{\text {bot }}$ (ref to Figure 5a), (b) current $I_{\text {mid }}$ (ref to Figure 5a), (c) current $I_{\text {top }}$ (ref to Figure 5a). 


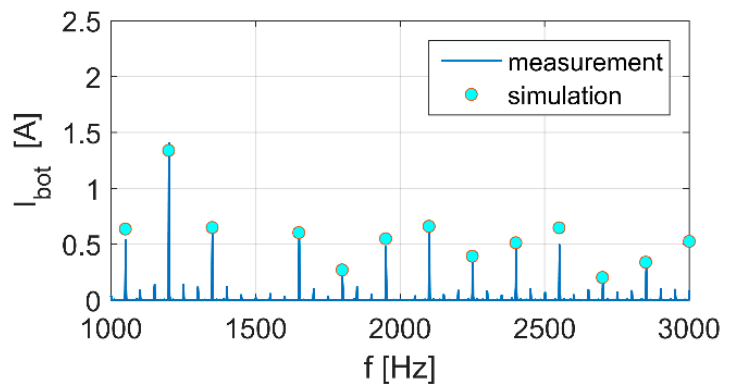

(a)

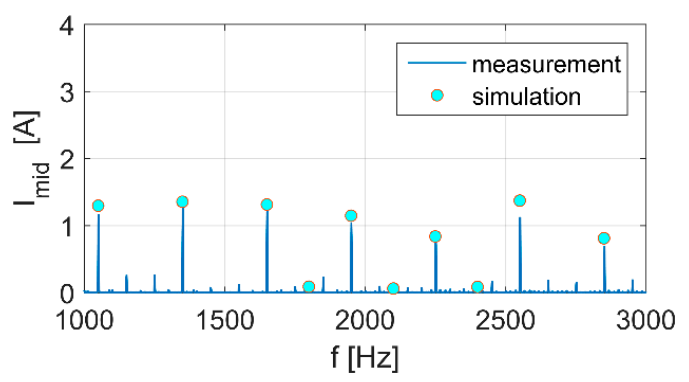

(b)

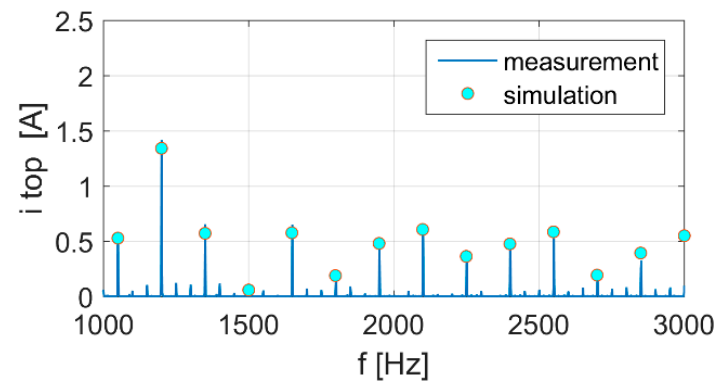

(c)

Figure 9. Spectrum of DC-link currents in VSI NPC inverter with SHE-PWM (a) current $\mathrm{I}_{\mathrm{bot}}$ (ref to Figure 5a) (b) current $I_{\text {mid }}$ (ref to Figure 5a) (c) current $I_{\text {top }}$ (ref to Figure 5a).

\section{Current Spectrum Generated by 3-lvl Laboratory Traction Drive}

In this section, the results of simulations for a three-level, laboratory-size inverter during regenerative braking have been presented. The spectra of DC-link harmonics has been analyzed to reveal the differences between SPWM and SHE-PWM during vehicles braking. The aim of this section is to present the influence of the SHE application on current harmonics in the band of frequency $1500-3000 \mathrm{~Hz}$, generated by a traction vehicle during braking.

\subsection{Regenerative Braking with SPWM}

Figures 10 and 11 present the simulations of DC-link currents in an NPC 3 level inverter during regenerative operation with SPWM modulation. Simulations were conducted for modulation index $\mathrm{M} 1=0.9$, and fundamental frequency $\mathrm{f}_{\mathrm{f}}=50 \mathrm{~Hz}$, and carrier frequency $\mathrm{f}_{\mathrm{c}}=850 \mathrm{~Hz}$. The third harmonic of a fundamental component $\left(3 \mathrm{f}_{\mathrm{f}}\right)$ was observed in all three wires. The first harmonic of the carrier has significant value as well. Figure 12 presents the result of the spectral analysis of the catenary current. The characteristic feature of presented modulation is that the carrier harmonic $\left(f_{c}\right)$ is present in DC-link and it is canceled in the catenary current. The pattern of generated harmonics is typical for SPWM with a natural sampling technique. 


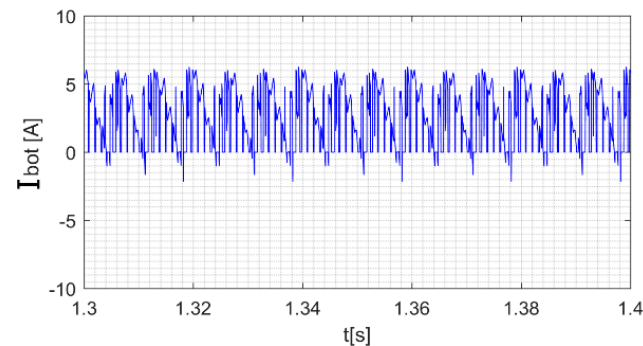

(a)

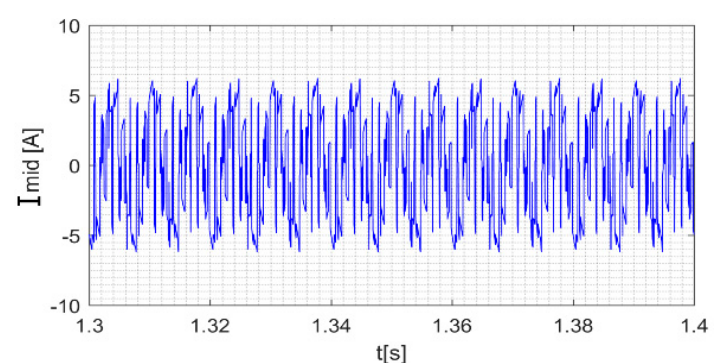

(b)

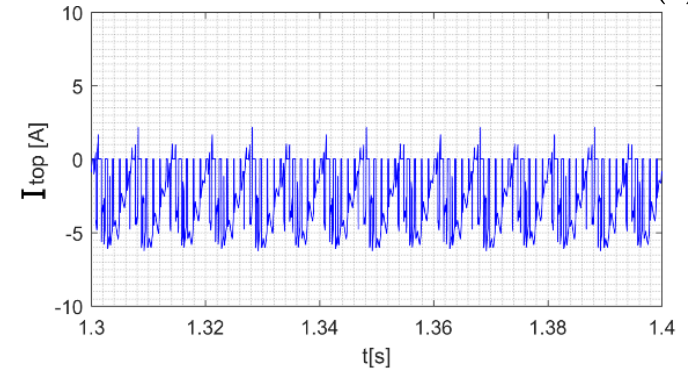

(c)

Figure 10. Waveform of DC-link currents during regenerative operation of 3-level NPC inverter with SPWM (current description refers to Figure 5) (a) current $\mathrm{I}_{\text {bot }}(\mathbf{b})$ current $\mathrm{I}_{\text {mid }}$ (c) current $\mathrm{I}_{\text {top }}$.

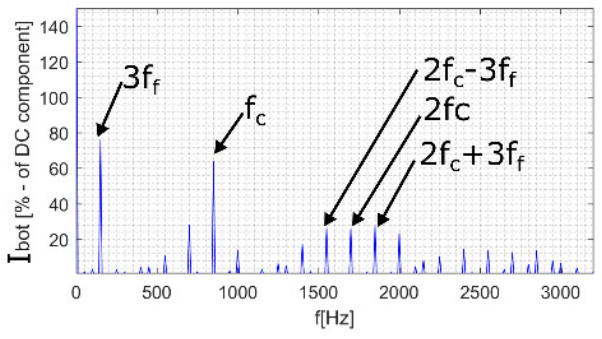

(a)

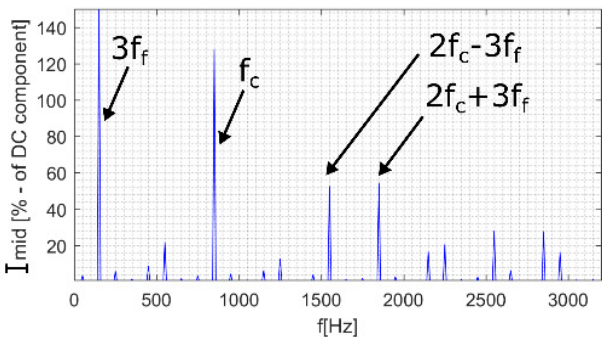

(b)

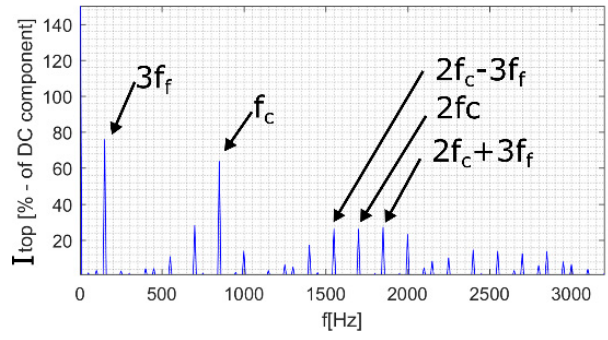

(c)

Figure 11. Spectra of DC-link currents during regenerative operation of 3-level NPC inverter with SPWM (current description refer to Figure 5) (a) current $\mathrm{I}_{\text {bot }}$, (b) current $\mathrm{I}_{\text {mid }}$, (c) current $\mathrm{I}_{\text {top. }}$.

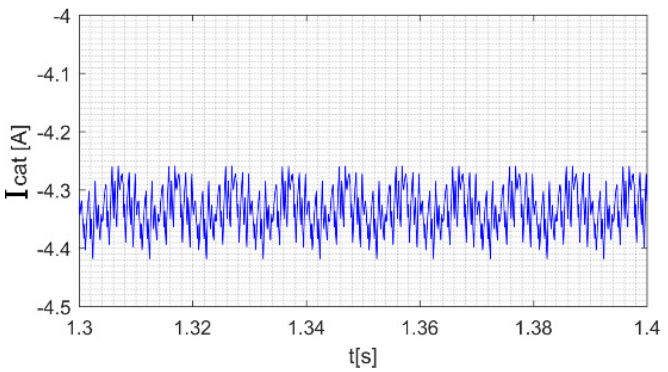

(a)

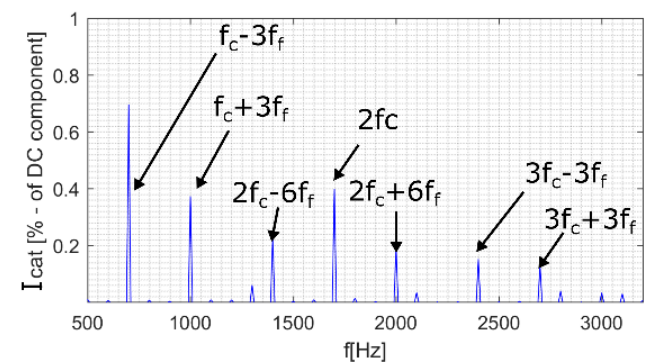

(b)

Figure 12. Simulated catenary current of 3-level NPC inverter with SPWM (a) waveform, (b) spectrum. 


\subsection{Regenerative Braking with SHE}

The similar study, compared to the ones presented in Section 3.1, has been carried out for the SHE modulation. The goal was to identify which harmonic circulates in the DC-link and which transfers to catenary during regenerative braking with SHE modulation. The operating point studied in this section was defined by $\mathrm{M} 1=0.9, \mathrm{f}_{\mathrm{f}}=50 \mathrm{~Hz}$, and $\mathrm{N}=9$, and the following harmonics were eliminated from output voltage: 5th, 7th, 11th, 13th, 17th, 19th, 29th, 31st. Figures 13 and 14 presents simulated DC-link current waveform and spectrum respectively. Elimination of 29th, 31st harmonics from the output voltage results with elimination of 30th harmonics from catenary current (Figure 15).

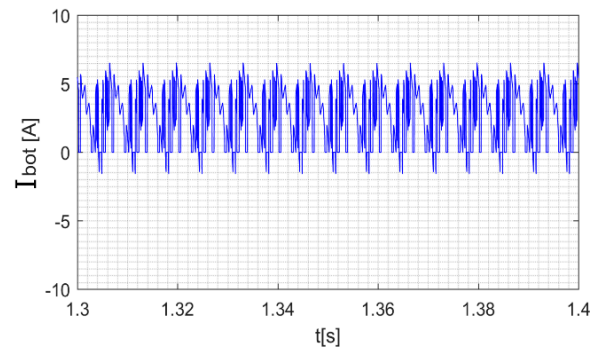

(a)

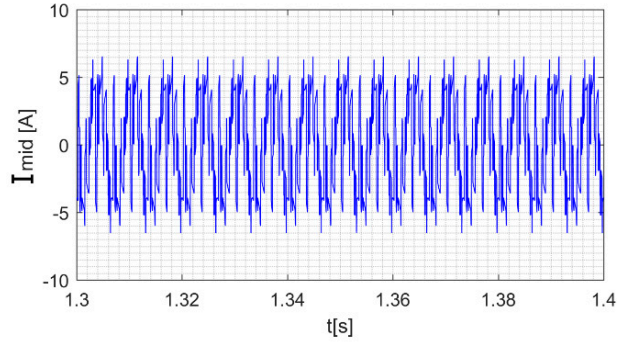

(b)

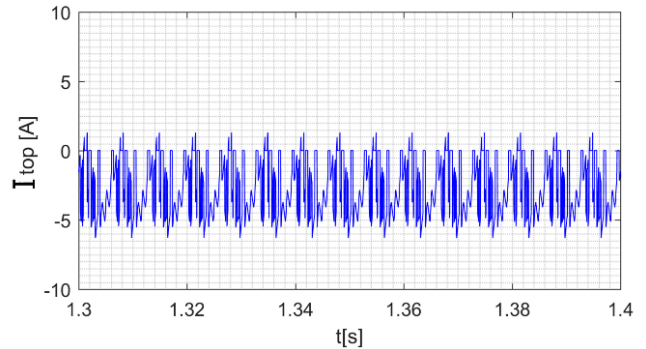

(c)

Figure 13. Waveform of DC-link currents during regenerative operation of a 3 lvl NPC inverter with SHE-PWM (current description refers to Figure 5) (a) current $\mathrm{I}_{\mathrm{bot}}$, (b) current $\mathrm{I}_{\text {mid }}$, (c) current $\mathrm{I}_{\text {top. }}$.

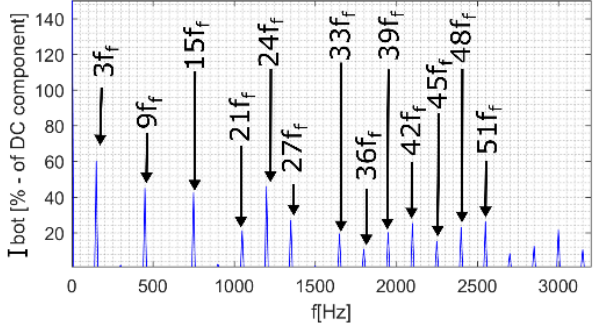

(a)

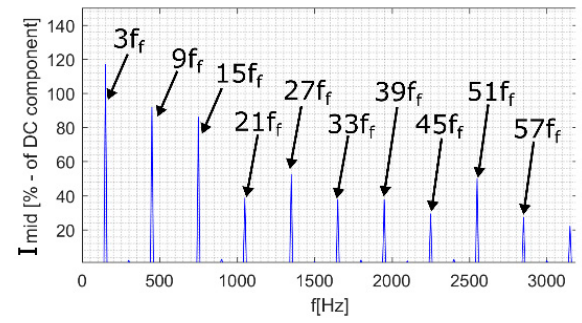

(b)

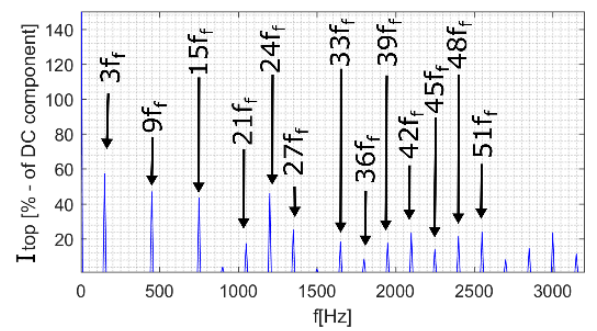

(c)

Figure 14. Spectra of DC-link currents during regenerative operation of a 3-level NPC inverter with SHE-PWM (current description refer to Figure 5) (a) current $\mathrm{I}_{\text {bot }},(\mathbf{b})$ current $\mathrm{I}_{\text {mid }}$, (c) current $\mathrm{I}_{\text {top. }}$. 


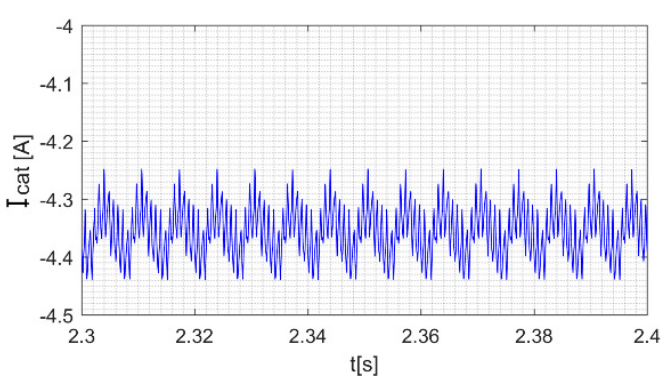

(a)

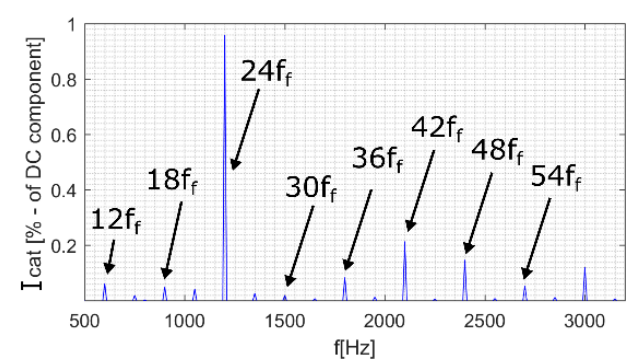

(b)

Figure 15. Simulated catenary current of a 3-level NPC inverter with SHE-PWM (a) waveform, (b) spectrum.

\section{Results for a $3 \mathrm{kV}$ DC Railway System}

\subsection{Model Scalling for $3 \mathrm{kV} D C$}

The attention in this section is focused on the study of current harmonics circulation in the $3 \mathrm{kV}$ DC railway system with a vehicle operating in a regenerative braking mode (Figure 16). The results were achieved by using the model of the braking drive, presented and verified in Section 2, and scaled to the $3 \mathrm{kV}$ by application of parameters from Table 1 . The load for the braking energy was modelled as the DC current source $\left(\mathrm{I}_{\mathrm{L}}\right)$ with an input gamma filter $\left(\mathrm{L}_{\mathrm{L}}, \mathrm{C}_{\mathrm{L}}\right)$. This model is able to represent both the accelerating vehicle and the energy source or storage device. The $\mathrm{I}_{\mathrm{LOAD}}$ current represents the energy drawn by the LOAD from the system, without harmonics generated by the device. Thus, the harmonics generated by the braking vehicle will not be interfered by other sources. It makes a clear picture of harmonics generated by the vehicle and circulating in the system without any additional disturbances. The model of the traction substation (TS) was simplified to the voltage source with internal resistance $\left(\mathrm{R}_{\mathrm{IN}}\right)$ and diode blocking the reverse circulation of energy through a rectifier. To reduce the computational effort a single drive was modelled $(500 \mathrm{~kW})$. Results have been referred to the limits recalculated by the following formula:

$$
i_{\mathrm{ln}}=\frac{i_{\mathrm{lo}}}{\left(\frac{n_{m}}{n_{i n v}}\right) \cdot \sqrt{n_{v}}}
$$

where:

$i_{\mathrm{ln}}$-limits recalculated,

$i_{\text {lo }}$-original limits,

$n_{m}$-number of motors on-board single vehicle,

$n_{\text {inv }}$-number of inverters on-board single vehicle,

$n_{v}$-number of vehicles in the traction set.

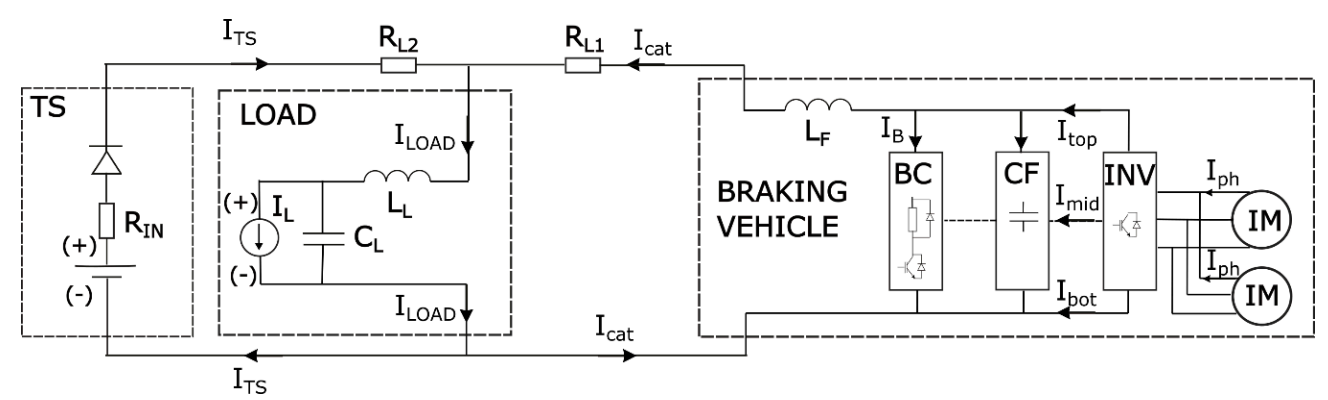

Figure 16. The simulation model of $3 \mathrm{kV}$ DC system with braking vehicle and the load for regenerated energy. 
Formula (9) was developed with the following assumptions: algebraic summation of current harmonics generated on-board single vehicle and geometric summation of current harmonics generated on-board different vehicles in the same traction set (based on general law for summation of harmonic current from different harmonic sources presented in IEC 61000-3-6).

\subsection{Results of Simulation}

The traction drive operates in variable conditions, such as variable load. In the proposed methodology, the load is modelled by the electromotive force $(\mathrm{EMF})$ as the perfect AC voltage source. Figure 17 presents the EMF calculated for $\mathrm{f}_{\mathrm{f}}=52 \mathrm{~Hz}$ and M1 $=0.9$ for different load conditions of a $500 \mathrm{~kW}$ induction motor. Both, modulo and argument of EMF were determined for motoring (positive values of a fundamental phase current, $\mathrm{I}_{\mathrm{ph} 1}$ ) and braking (negative values of a fundamental phase current, $\mathrm{I}_{\mathrm{ph} 1}$ ). The fundamental phase current was calculated to represent a load from $50 \%$ to $150 \%$ of nominal value. The parameters of EMF are not symmetrical for motor and braking operation. The reason is that during motor operation, the reactive power consumed by the magnetization branch is taken from the inverter, and in braking operation it is taken from the EMF. Thus, this phenomena gives asymmetry between motor and braking operation and can be observed in Figure 17.

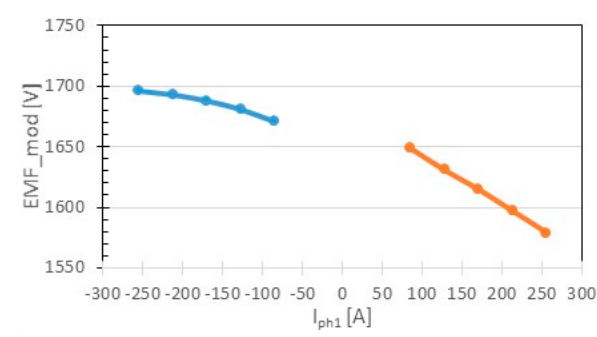

(a)

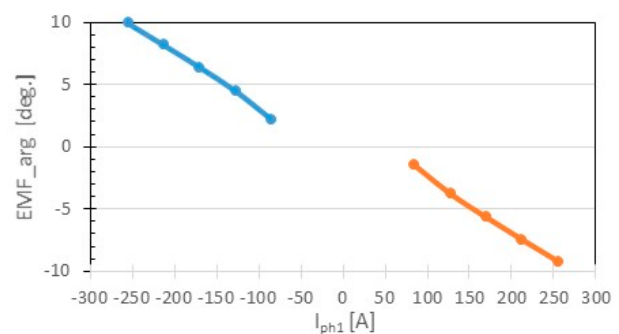

(b)

Figure 17. The electromotive force determined for motor and braking operation (a) modulo, (b) argument.

Figures 18 and 19 present the simulated spectra of phase current for different load conditions. It can be observed that phase current harmonics do not depend on load conditions (fundamental component) which refers to the assumption that slip for higher harmonics is close to zero. The proposed simulation model correctly models this phenomenon for both SPWM and SHE-PWM. The next step was to compare the catenary current $\left(\mathrm{I}_{\mathrm{cat}}\right)$ harmonics for the motor and braking operating mode. The results of this comparison, for unlimited system receptivity for regenerated power, are presented in Figure 20 for SPWM and Figure 21 for SHE-PWM. It can be noticed that for perfect conditions, the catenary current harmonics are similar for motor and braking operation.

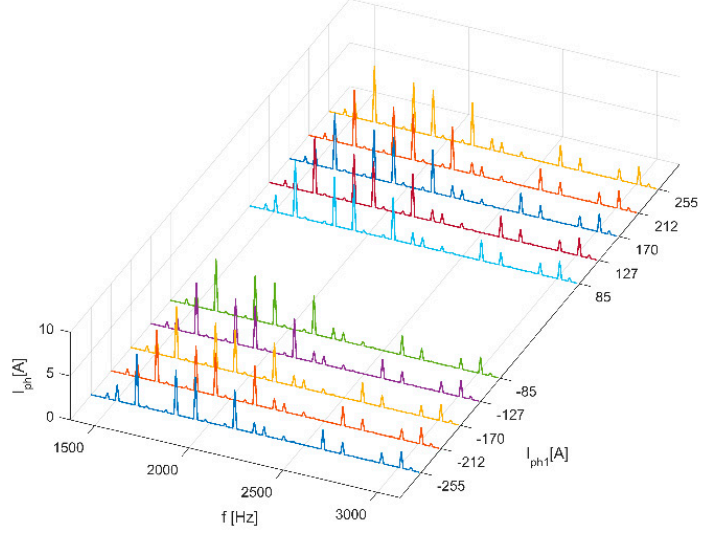

Figure 18. Spectrum of the phase current $\left(\mathrm{I}_{\mathrm{ph}}\right)$ as the function of fundamental component $\left(\mathrm{I}_{\mathrm{ph} 1}\right)$ for SPWM. 


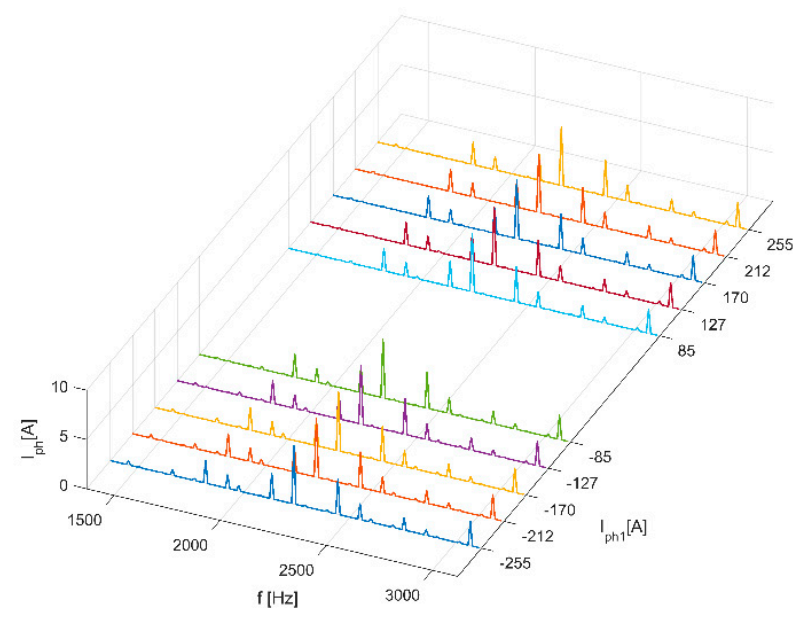

Figure 19. Spectrum of the phase current $\left(\mathrm{I}_{\mathrm{ph}}\right)$ as the function of fundamental component $\left(\mathrm{I}_{\mathrm{ph} 1}\right)$ for $\mathrm{SHE}$.

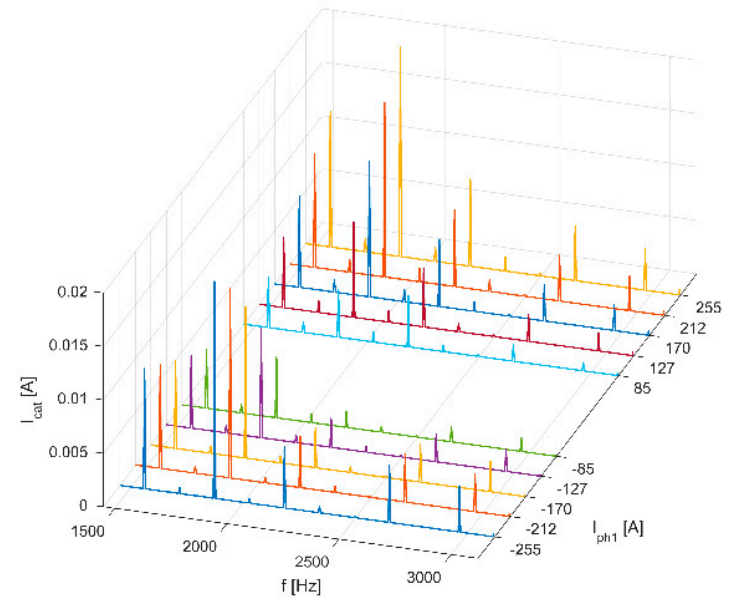

Figure 20. Spectrum of the catenary current $\left(\mathrm{I}_{\mathrm{cat}}\right)$ as the function of fundamental component $\left(\mathrm{I}_{\mathrm{ph} 1}\right)$ for SPWM.

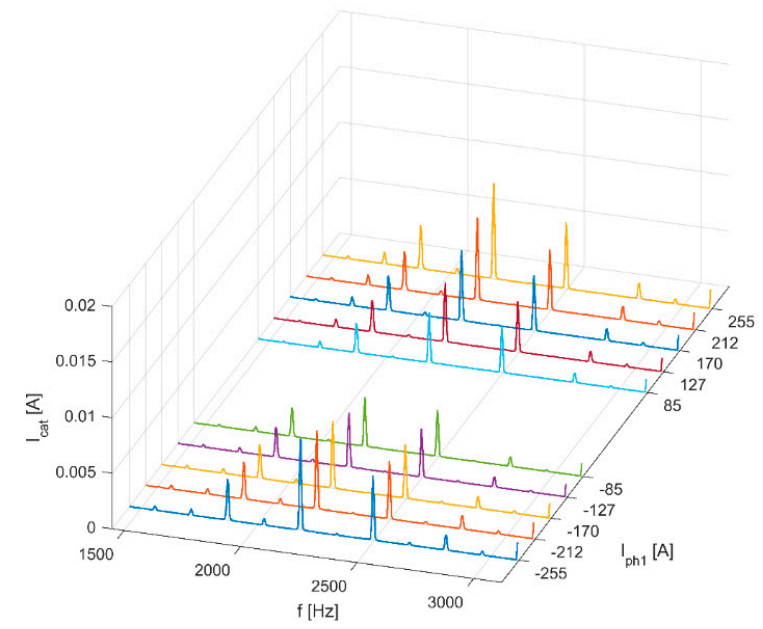

Figure 21. Spectrum of the catenary current $\left(\mathrm{I}_{\mathrm{cat}}\right)$ as the function of fundamental component $\left(\mathrm{I}_{\mathrm{ph} 1}\right)$ for SHE.

The next experiment was developed to prove that SHE-PWM is beneficial in the application for regenerative braking mode regarding control of a catenary current harmonic. Figure 22 presents 
simulation results for the model from Figure 16 where $\mathrm{M} 1=0.9 ; \mathrm{f}_{\mathrm{f}}=52 \mathrm{~Hz} ; \mathrm{f}_{\mathrm{C}}=18 \cdot \mathrm{ff} ; \mathrm{I}_{\mathrm{LOAD}}=400 \mathrm{~A}$; $\mathrm{I}_{\mathrm{ph} 1}=-255 \mathrm{~A}$ (per motor). The parameters of the vehicle on-board filters were as follows $\mathrm{L}_{\mathrm{F}}=4.7 \mathrm{mH}$; $\mathrm{C}_{\mathrm{F}}=6.5 \mathrm{mF}$. The receiver for the recuperated energy was assumed to be an energy storage device with the input filter $\mathrm{L}_{\mathrm{L}}=4 \mathrm{mH} ; \mathrm{C}_{\mathrm{L}}=0.4 \mathrm{mF}$. Results presented in Figure 22 refer to the limits recalculated using Formula (9) for two vehicles $\left(n_{v}=2\right)$ with three 3-level inverters on-board each vehicle $\left(n_{\text {inv }}=3\right)$ and six induction motors on-board each vehicle $\left(\mathrm{n}_{\mathrm{m}}=6\right)$. It can be observed that the violation of the limits is present for this operating point. For the same conditions, the SHE-PWM was applied, and the results are presented in Figure 23. The following voltage harmonics were eliminated: 5th, 7th, 11th, 13th, 17th, 19th, 29th, 31st. Elimination of these voltage harmonics provides the modulation which generates $\mathrm{I}_{\mathrm{CAT}}$ harmonics below assumed limits (Figure 23) The SHE gives the possibility to control current harmonics during regenerative braking in such a way as to avoid assumed limits. However, the $42 \mathrm{nd}$ harmonic $(2184 \mathrm{~Hz})$ of $\mathrm{I}_{\mathrm{CAT}}$ is very close to the limit. In practice, the margin is required. Assuming 10\% of the required margin (between harmonic amplitude and the limit), the SHE was not able to find feasible solution. To solve this issue with the same number of switching angles, the Selective Harmonic Mitigation was applied (SHM-PWM). The following pattern of elimination and mitigation of voltage harmonics was developed: 5 th $=0,7$ th $=0,11$ th $=0,13$ th $=0,17$ th $=0$, 19 th $=5 \%, 25$ th $=20 \%, 29$ th $=5 \%$. Figure 24 presents results for SHM-PWM and the margin between current harmonic and limit is visible.

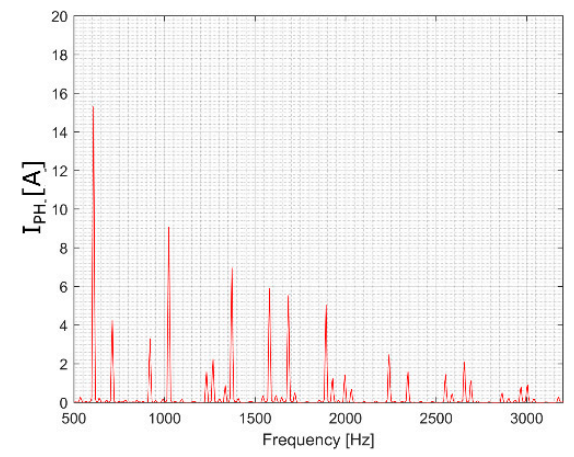

(a)

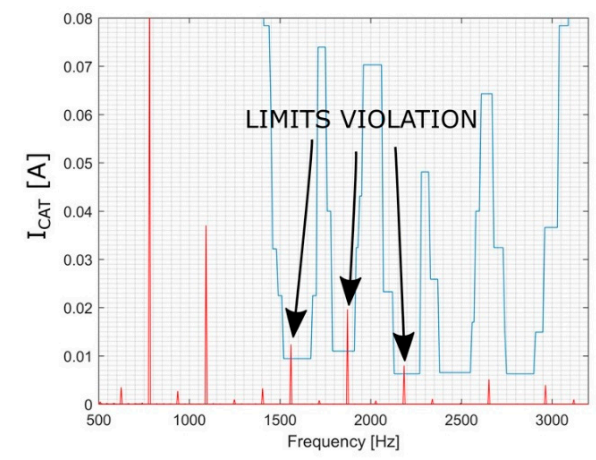

(b)

Figure 22. Simulation results for regenerative braking with SPWM (a) $\mathrm{I}_{\mathrm{ph}}$-phase current, (b) $\mathrm{I}_{\text {cat }}$ - catenary current.

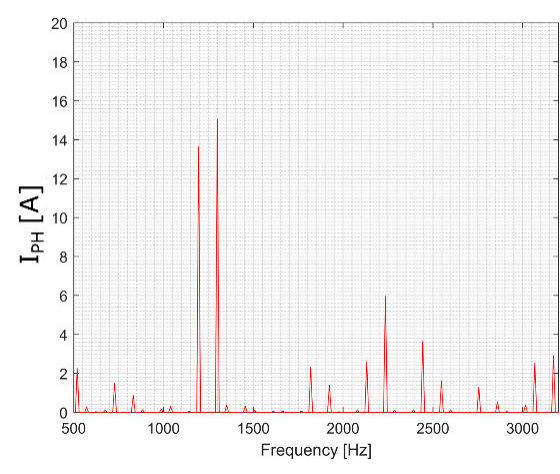

(a)

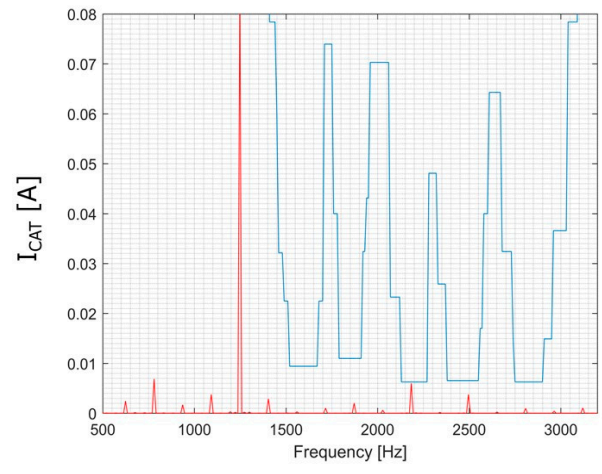

(b)

Figure 23. Simulation results for regenerative braking with SHE-PWM (a) $\mathrm{I}_{\mathrm{ph}}$-phase current, (b) $\mathrm{I}_{\text {cat }}$-catenary current. 


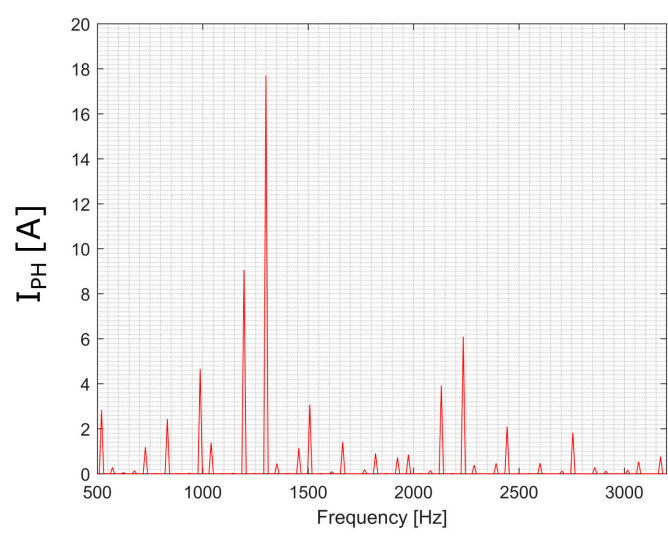

(a)

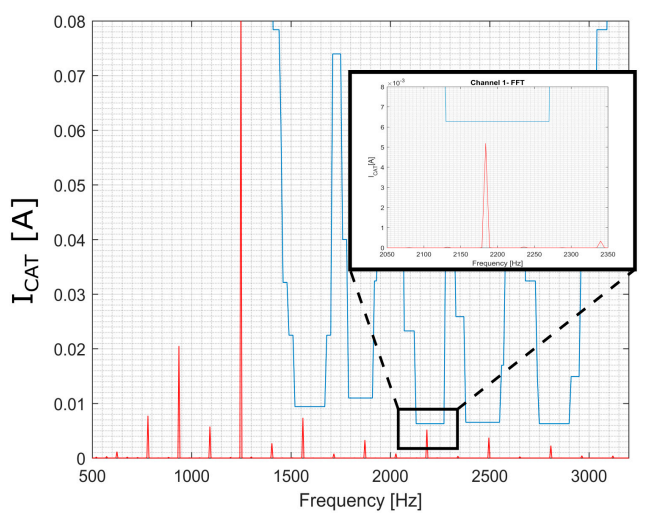

(b)

Figure 24. Simulation results for regenerative braking with SHM-PWM (a) $\mathrm{I}_{\mathrm{ph}}$-phase current, (b) $\mathrm{I}_{\text {cat }}$ - catenary current.

\subsection{The Influence of a Braking Chopper}

The previous study was carried out with an assumption that the DC-power supply is fully receptive. The case presented in this section assumes that DC system cannot absorb all regenerated energy. Thus, the current of the energy storage device is limited to $300 \mathrm{~A}$ (Figure 25) In such a case, the braking chopper onboard the vehicle must be activated. In this section, the influence of a braking chopper on the catenary current harmonics is presented. In a three-level NPC inverter a braking chopper is divided into two sections. The regular operation of the chopper generates harmonics on the fundamental chopper frequency and its multiplications.

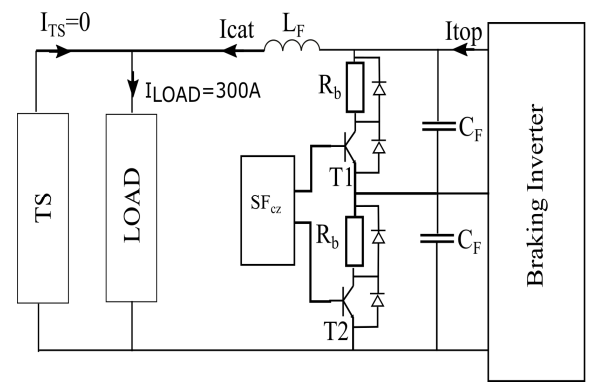

(a)

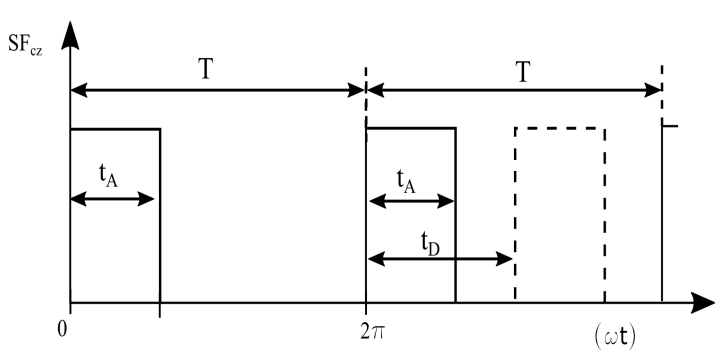

(b)

Figure 25. Schema of braking circuit (a) topology of braking chopper in 3 lvl NPC inverter, (b) switching function for chopper transistors.

In following part of this section an influence of a braking chopper on $\mathrm{I}_{\text {cat }}$ spectrum is presented. The chopper frequency is $\mathrm{fb}=900 \mathrm{~Hz}$. and braking resistor was $\mathrm{R}_{\mathrm{b}}=5 \Omega$ each. The $\mathrm{I}_{\mathrm{LOAD}}$ was limited to $300 \mathrm{~A}$ to model the limited receptivity of the DC-system. The assumption was to keep the DC-link voltage close to $3600 \mathrm{~V}$. The choppers were operating during this experiment with duty cycle 0.3. Different values of the shift (shifted braking pulsation (SBP)) were implemented between chopper pulses (Figure 26) to investigate the possibilities of reducing current harmonics generated by the chopper below assumed limits. The shift was defined by the following formula:

$$
\text { SHIFT }=\frac{t_{D}}{T}
$$

where:

$t_{D}$-is a time delay of every second pulse, 
T-period of the chopper pulsation.

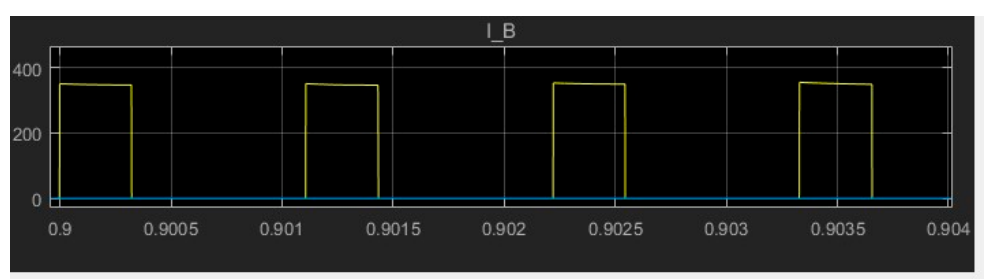

(a)

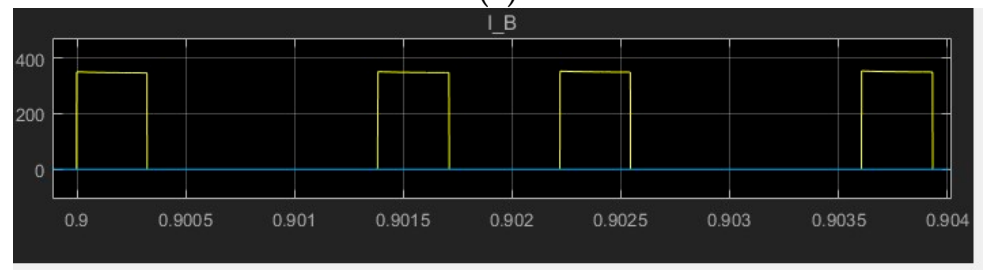

(b)

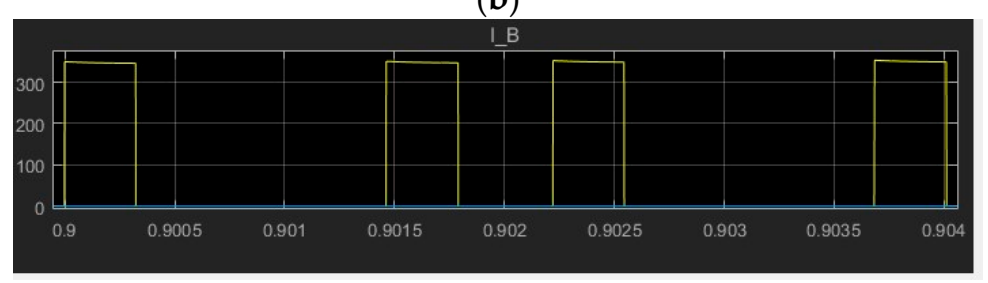

(c)

Figure 26. Current of braking choppers $\left(\mathrm{I}_{\mathrm{B}}[\mathrm{A}]\right)$ vs time $[\mathrm{s}]$ for $(\mathbf{a})$ shift $=0$, (b) shift $=0.25$, (c) shift $=0.32$.

Figure 27 presents the influence of a braking chopper on $\mathrm{I}_{\text {cat }}$ spectrum. The implementation of shift $=0.25$ eliminates harmonic $2 \mathrm{xfb}$, however it generates inter-harmonics $1.5 \mathrm{xfb}$ and $2.5 \mathrm{xfb}$. The optimum value of shift, in this case, was 0.32 (Figure 27c). The inter-harmonics were generated, but their values were reduced below limits. The $2 \mathrm{fb}$ harmonic was present but reduced as well. The proposed SBP was efficient for the presented operating point and it is worth further study and development. Moreover, to satisfy the margin between amplitudes of generated current, harmonics and imposed limits the SHM-PWM was implemented (Figure 27d) with the same pattern as proposed in Section 4.2. However, the problem of the lack of margin for harmonics generated by chopper remains. To solve this problem, the variable mixed cycle techniques (MDC). The idea of MDC was explained in Figure 28. In MDC the assumed duty cycle of braking chopper is achieved as the mean value of two duty cycles $\mathrm{k}_{\mathrm{A}}$ and $\mathrm{k}_{\mathrm{B}}$ e.g., $\mathrm{k}=0.3$ can be generated by $\mathrm{k}_{\mathrm{A}}=0.1$ and $\mathrm{k}_{\mathrm{B}}=0.5$. In Figure 29 it is presented that application of MDC provides margins between amplitudes of current harmonics generated by chopper operation and assumed limits. 


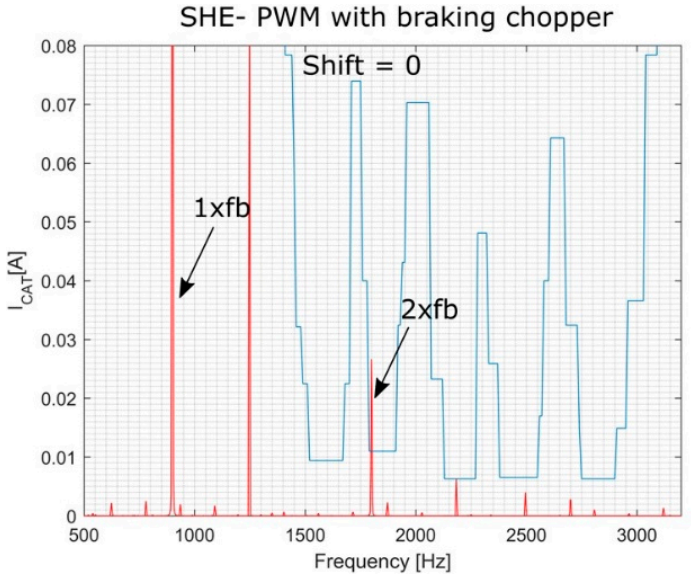

(a)

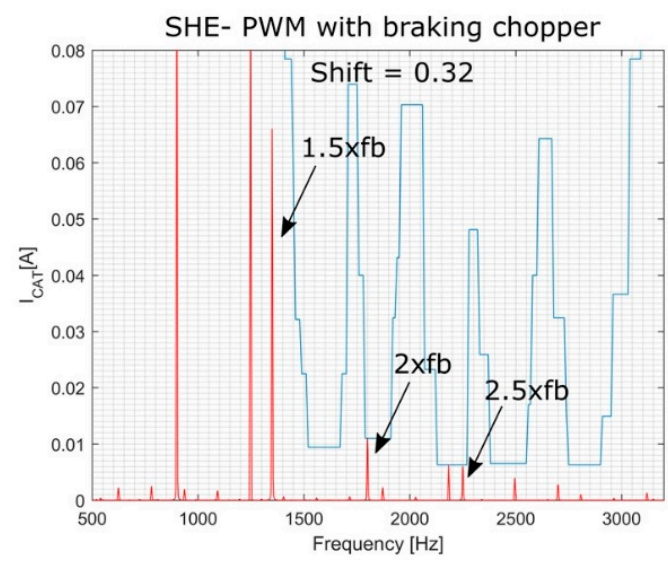

(c)

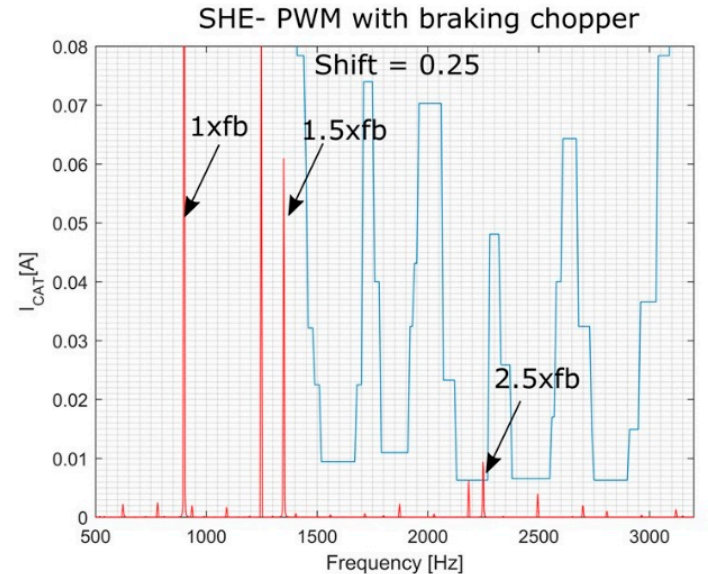

(b)

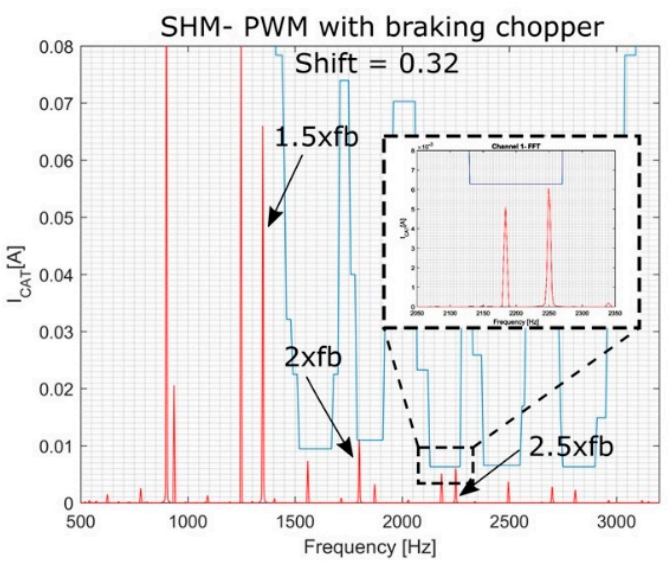

(d)

Figure 27. Catenary current harmonics for chopper braking operation (frequency of braking chopper $\mathrm{fb}=900 \mathrm{~Hz}$, duty cycle $\mathrm{k}=0.3$ ) (a) SHE-PWM with regular chopper braking, (b) SHE-PWM with chopper pulses with shift $=0.25$, (c) SHE-PWM with chopper pulses with shift $=0.32$, (d) SHM-PWM with chopper pulses with shift $=0.32$.

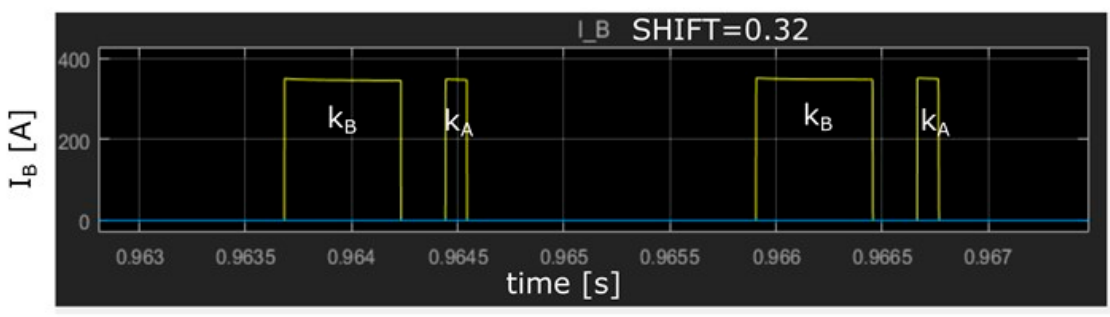

Figure 28. Current of braking choppers $\left(\mathrm{I}_{B}[\mathrm{~A}]\right)$ vs time $[\mathrm{s}]$ for mixed duty cycle $(\mathrm{MCD}) \mathrm{k}_{\mathrm{A}}=0.1$, $\mathrm{k}_{\mathrm{B}}=0.5$ (effective duty cycle $\mathrm{k}=0.3$ ). 


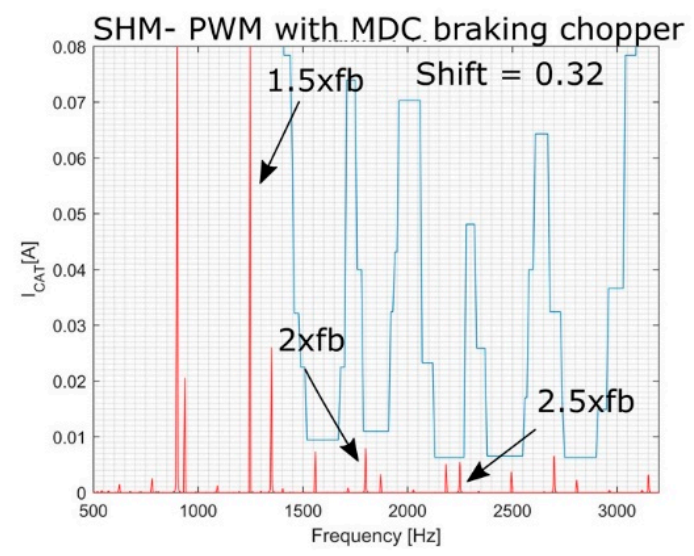

Figure 29. Catenary current harmonics for chopper braking operation (frequency of braking chopper $\mathrm{fb}=900 \mathrm{~Hz}$ ) for mixed duty cycle $(\mathrm{MCD}) \mathrm{k}_{\mathrm{A}}=0.1, \mathrm{k}_{\mathrm{B}}=0.5$ (effective duty cycle $\mathrm{k}=0.3$ ).

More results for different duty cycles are presented in Figure 30. For every duty cycle of chopper there is a combination of Shift and MDC which allows to reduce amplitudes of harmonics generated by braking chopper below assumed limits. The proposed control over braking chopper, combined with SHM-PWM, gives control over current harmonics generated by the vehicle and allows them to not violate assumed limits for their amplitudes.

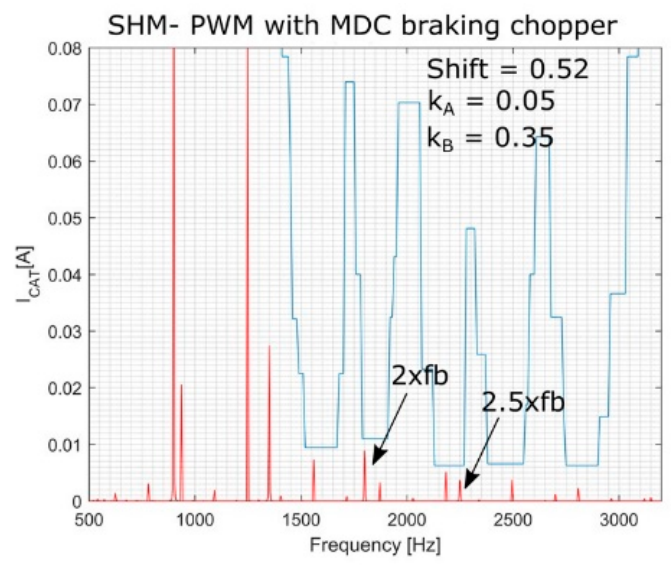

(a)

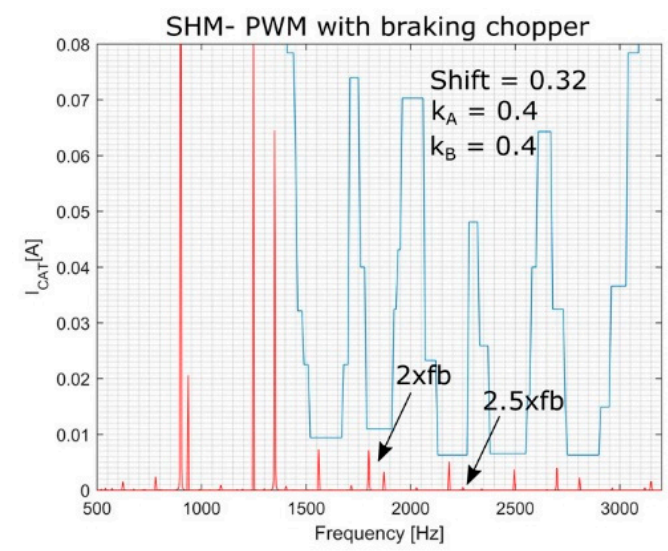

(b)

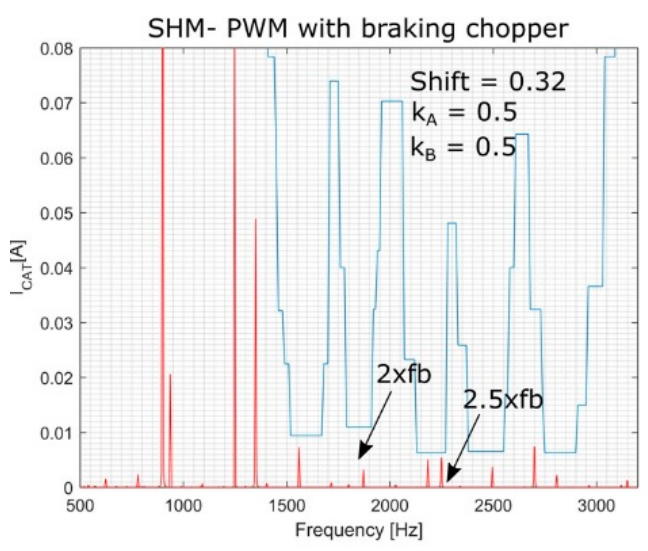

(c)

Figure 30. Catenary current harmonics for chopper braking operation (frequency of braking chopper $\mathrm{fb}=900 \mathrm{~Hz}$ ) for different duties (a) $\mathrm{k}=0.2$ with MDC; (b) $\mathrm{k}=0.4 ;(\mathbf{c}) \mathrm{k}=0.5$. 


\section{Conclusions}

The aim of this paper was to present the benefits of the application of SHE-PWM in a traction drive with a three-level inverter, to reduce specific current harmonics generated during regenerative braking. Moreover, the operation of braking choppers was taken into consideration. One operating point was chosen as a reference for the case study. The authors claim that SHE-PWM can be used in inverter's operating areas only where the typical modulations used in traction drives generate too high amplitudes of current harmonics and violate limits imposed by signaling system. Thus, there is no reason to study it in a whole range of operation during regenerative braking. It should be used as the interventional technique, where the probability of interference is high. However, the concern might be the applicability of SHE-PWM in real traction dives. Nowadays the implementation of SHE in traction drives by combining it with SVM is not an issue, due to rapid development of inverter controllers. Thus, its implementation was not a scope of this work. However, it is suggested to use SHE-PWM as the off-line technique, which means the switching angles should be pre-processed and stored as the lookup tables. It gives the opportunity to utilize a highly developed optimization algorithm without time pressure, typical for on-line techniques. The innovation of this paper is based on the presentation that SHE-PWM and SHM-PWM can be applied to control current harmonics as well during regenerative braking of a railway vehicle. Moreover the asymmetric technique of controlling a braking chopper in a three-level inverter was proposed to avoid the generation of current harmonics by a chopper in bands of frequency where limits are imposed on them. For low values duty cycles, the mixed duty cycle technique (MDC) was proposed to avoid generation of current harmonics above assumed limits. The proposed combination of SHM-PWM and chopper operation on braking operation of the vehicle allows the tuning of the amplitudes of catenary current harmonic below assumed limits to meet compatibility requirements. In this paper only examples have been presented. The further analysis are required for generalization of proposed technique. The dynamic performance of the proposed SHM-PWM will be investigated in the next research.

Author Contributions: M.S.: Methodology, theoretical analysis, software, simulations; P.C.: Development of laboratory setup, measurements; A.S.: Supervision, literature research, text editing. All authors have read and agreed to the published version of the manuscript.

Funding: This research received no external funding.

Conflicts of Interest: The authors declare no conflict of interest.

\section{References}

1. Kleftakis, V.A.; Hatziargyriou, N.D. Optimal control of reversible substations and wayside storage devices for voltage stabilization and energy savings in metro railway networks. IEEE Trans. Transp. Electrif. 2019, 5, 515-523. [CrossRef]

2. Alfieri, L.; Battistelli, L.; Pagano, M. Impact on railway infrastructure of wayside energy storage systems for regenerative braking management: A case study on a real Italian railway infrastructure. IET Electr. Syst. Transp. 2019, 9, 140-149. [CrossRef]

3. Aguado, J.A.; Racero, A.J.S.; De La Torre, S. Optimal operation of electric railways with renewable energy and electric storage systems. IEEE Trans. Smart Grid 2018, 9, 993-1001. [CrossRef]

4. Cui, G.; Luo, L.; Liang, C.; Hu, S.; Li, Y.; Cao, Y.; Xie, B.; Xu, J.; Zhang, Z.; Liu, Y.; et al. Supercapacitor Integrated Railway Static Power Conditioner for Regenerative Braking Energy Recycling and Power Quality Improvement of High-Speed Railway System. IEEE Trans. Transp. Electrif. 2019, 5, 702-714. [CrossRef]

5. Jiang, Y.; Liu, J.; Tian, W.; Shahidehpour, M.; Krishnamurthy, M. Energy Harvesting for the Electrification of Railway Stations: Getting a charge from the regenerative braking of trains. IEEE Electrif. Mag. 2014, 2, 39-48. [CrossRef]

6. De La Torre, S.; Sánchez-Racero, A.J.; Aguado, J.A.; Reyes, M.; Martínez, O. Optimal Sizing of Energy Storage for Regenerative Braking in Electric Railway Systems. IEEE Trans. Power Syst. 2015, 30, 1492-1500. [CrossRef]

7. Radu, P.V.; Szelag, A.; Steczek, M. On-Board Energy Storage Devices with Supercapacitors for Metro Trains-Case Study Analysis of Application Effectiveness. Energies 2019, 12, 1291. [CrossRef] 
8. Jefimowski, W.; Nikitenko, A.; Drążek, Z.; Wieczorek, M. Stationary supercapacitor energy storage operation algorithm based on neural network learning system. Bull. Pol. Acad. Sci. Tech. Sci. 2020, 68. [CrossRef]

9. Jabr, R.A.; Džafić, I. Solution of DC railway traction power flow systems including limited network receptivity. IEEE Trans. Power Syst. 2018, 33, 962-969. [CrossRef]

10. Zhang, G.; Tian, Z.; Tricoli, P.; Hillmansen, S.; Wang, Y.; Liu, Z. Inverter Operating Characteristics Optimization for DC Traction Power Supply Systems. IEEE Trans. Veh. Technol. 2019, 68, 3400-3410. [CrossRef]

11. Jefimowski, W.; Szelag, A. The multi-criteria optimization method for implementation of a regenerative inverter in a $3 \mathrm{kV}$ DC traction system. Electr. Power Syst. Res. 2018, 161, 61-73. [CrossRef]

12. Domínguez, M.; Fernández-Cardador, A.; Cucala, A.P. Pecharromán RR. Energy savings in metropolitan railway substations through regenerative energy recovery and optimal design of ATO speed profiles. IEEE Trans. Autom. Sci. Eng. 2012, 9, 496-504. [CrossRef]

13. Liu, J.; Guo, H.; Yu, Y. Research on the Cooperative Train Control Strategy to Reduce Energy Consumption. IEEE Trans. Intell. Transp. Syst. 2017, 18, 1134-1142. [CrossRef]

14. Ronanki, D.; Singh, S.A.; Williamson, S.S. Comprehensive Topological Overview of Rolling Stock Architectures and Recent Trends in Electric Railway Traction Systems. IEEE Trans. Transp. Electrif. 2017, 3, 724-738. [CrossRef]

15. Szelag, A.; Patoka, M. Issues of low frequency electromagnetic disturbances measurements in traction vehicles equipped with power electronics drive systems. Przeglad Elektrotech. 2013, 89, 290-296.

16. Tao, H.; Hu, H.; Wang, X.; Blaabjerg, F.; He, Z. Impedance-Based Harmonic Instability Assessment in a Multiple Electric Trains and Traction Network Interaction System. IEEE Trans. Ind. Appl. 2018, 54, 5083-5096. [CrossRef]

17. Mariscottii, A.; Ogunsola, A. Lecture Notes in Electrical Engineering Series: Electromagnetic Compatibility in Railways: Analysis and Management; Springer: Berlin, Germany, 2012.

18. Hu, H.; Shao, Y.; Tang, L.; Ma, J.; He, Z.; Gao, S. Overview of Harmonic and Resonance in Railway Electrification Systems. IEEE Trans. Ind. Appl. 2018, 54, 5227-5245. [CrossRef]

19. Baboszin, V.A.; Gavrilovich, B.; Jakovlev, A.A. To the study of analysis on how harmonic radio interference affects the power supply systems of railway transport, Mathematical modeling. Autom. Control Process 2020, 2, 36-45.

20. Adamski, D.; Ortel, K.; Zawadka, Ł. Unified verification method of electromagnetic compatibility between rolling stock and train detection systems. In Proceedings of the Global Debate on Mobility Challenges for the Future Society, Warsaw, Poland, 15-16 November 2018.

21. Adamowicz, M.; Szewczyk, J. Research works on new solutions applied in traction drives supplied by $3 \mathrm{kV}$ DC coulud reduce energy losses and EMC problems [SiC-Based Power Electronic Traction Transformer-(PETT) for $3 \mathrm{kV}$ DC Rail Traction]. Energies 2020, 13, 5573. [CrossRef]

22. Mariscotti, A. Impact of Rail Impedance Intrinsic Variability on Railway System Operation, EMC and Safety. Int. J. Electr. Comput. Eng. 2020, 11, 17-26.

23. BSI Standards Publication. EN 50238-1:2019, Railway Applications-Compatibility between Rolling Stock and Train Detection Systems; BSI Standards Publication: London, UK, 2019.

24. Furman, J.; Białon, A. Influence of Commutation Disturbances on Analysis of Harmonics in Traction Current (In Polish: Wpływ zakłóceń Komutacyjnych na Analizę Harmonicznych w Prądzie Trakcyjnym); Railway Report, No 187; Instytut Kolejnictwa: Warsaw, Poland, 2020. [CrossRef]

25. Durzyński, Z.; Łatowski, M. PKP requirements on electromagnetic disturbances versus other railway infrastructure operators (In Polish: Wymagania PKP w zakresie zakłóceń elektromagnetycznych na tle innych zarządów kolei). In Proceedings of the Research-Technical Conference-Influence of Electric Traction on Environment, Zakopane, Poland, 14-16 October 1999; pp. 14-16.

26. Białon, A. Deriving Limits of Disturbances Parameters for Command, Control and Signaling Systems and Traction Vehicles, Research Work CNTK 6915/23; CNTK: Warsaw, Poland, 1999.

27. Requirements towards Allowed Limits and Parameters of Disturbances for Devices of Track Occupancy Control on Railway Lines Operated by PKP PLK S.A., Ie-115, Warsaw, Poland. 2015. Available online: https://www.plk-sa.pl/files/public/user_upload/pdf/Akty_prawne_i_przepisy/Instrukcje/Wydruk/ Wymagania_Ie_-115_internet.pdf (accessed on 1 November 2020). 
28. Dahidah, M.S.A.; Konstantinou, G.; Agelidis, V.G. A Review of Multilevel Selective Harmonic Elimination PWM: Formulations, Solving Algorithms, Implementation and Applications. IEEE Trans. Power Electron. 2015, 30, 4091-4106. [CrossRef]

29. Steczek, M.; Chudzik, P.; Lewandowski, M.; Szelag, A. PSO-Based Optimization of DC-Link Current Harmonics in Traction VSI for Electric Vehicle. IEEE Trans. Ind. Electron. 2020, 67, 8197-8208. [CrossRef]

30. Napoles, J.; Leon, J.I.; Portillo, R.; Franquelo, L.G.; Aguirr, M.A. Selective Harmonic Mitigation Technique for High-Power Converters. IEEE Trans. Ind. Electron. 2009, 57, 2315-2323. [CrossRef]

31. Leon, J.L.; Kouro, S.; Franquelo, L.G.; Rodrigez, J.; Wu, B. The Essential Role and the Continuous Evolution of Modulation Techniques for Voltage-Source Inverters in the Past, Present, and Future Power Electronics. IEEE Trans. Ind. Electron. 2016, 63, 2688-2701. [CrossRef]

Publisher's Note: MDPI stays neutral with regard to jurisdictional claims in published maps and institutional affiliations.

(C) 2020 by the authors. Licensee MDPI, Basel, Switzerland. This article is an open access article distributed under the terms and conditions of the Creative Commons Attribution (CC BY) license (http://creativecommons.org/licenses/by/4.0/). 